\title{
Epidemiology, Treatments, and Vaccine Development for Antimicrobial-Resistant Neisseria gonorrhoeae: Current Strategies and Future Directions
}

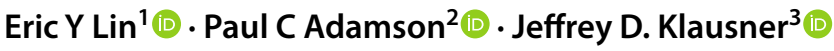

Accepted: 28 April 2021 / Published online: 7 June 2021

(c) The Author(s) 2021

\begin{abstract}
Neisseria gonorrhoeae is the second most common bacterial sexually transmitted infection in the world after Chlamydia trachomatis. The pathogen has developed resistance to every antibiotic currently approved for treatment, and multidrug-resistant strains have been identified globally. The current treatment recommended by the World Health Organization is ceftriaxone and azithromycin dual therapy. However, resistance to azithromycin and ceftriaxone are increasing and treatment failures have been reported. As a result, there is a critical need to develop novel strategies for mitigating the spread of antimicrobial-resistant $N$. gonorrhoeae through improved diagnosis and treatment of resistant infections. Strategies that are currently being pursued include developing molecular assays to predict resistance, utilizing higher doses of ceftriaxone, repurposing older antibiotics, and developing newer agents. In addition, efforts to discover a vaccine for $N$. gonorrhoeae have been reignited in recent years with the cross-protectivity provided by the $N$. meningitidis vaccine, with several new strategies and targets. Despite the significant progress that has been made, there is still much work ahead to combat antimicrobial-resistant $N$. gonorrhoeae globally.
\end{abstract}

\section{Key Points}

Antimicrobial resistance in Neisseria gonorrhoeae is on the rise globally; strains exhibiting resistance to both ceftriaxone and azithromycin have been reported in many countries.

Treatment strategies that are being pursued include developing molecular assays to predict resistance, repurposing antibiotics, and discovering novel antimicrobial agents.

Efforts to develop a vaccine for $N$. gonorrhoeae have been reignited in recent years with several new strategies and targets for vaccination.

Jeffrey D. Klausner

jklausne@usc.edu

Paul C Adamson

padamson@mednet.ucla.edu

1 David Geffen School of Medicine at UCLA, Los Angeles, CA, USA

2 Division of Infectious Diseases, David Geffen School of Medicine at UCLA, 10833 Le Conte Ave. CHS 52-215, Los Angeles, CA 90095, USA

3 Department of Preventive Medicine, Keck School of Medicine of USC, Los Angeles, CA, USA

\section{Introduction}

Neisseria gonorrhoeae is a sexually transmitted infection (STI) that affects both men and women. It is a Gramnegative diplococci that can infect the urogenital, rectal, and pharyngeal sites [1]. While males and females can both experience dysuria and purulent urethral discharge, the majority of cases of gonorrhea are asymptomatic [2]. Untreated infections can cause severe complications, ranging from epididymitis and salpingitis to pelvic inflammatory disease, ectopic pregnancy, and infertility. Gonorrhea can also complicate pregnancy and be transmitted to children, causing blindness if untreated. N. gonorrhoeae, like other STIs, can facilitate the transmission and acquisition of the human immunodeficiency virus [3].

Overall, $N$. gonorrhoeae is a major public health threat worldwide. It is the second most common bacterial STI in the world after Chlamydia trachomatis [4]. The World Health Organization (WHO) estimated there were 87 million new $N$. gonorrhoeae cases worldwide in 2016, an increase from 78 million in 2012 [5, 6].

Complicating the increase of $N$. gonorrhoeae infections observed globally has been the emergence of antimicrobial-resistant $N$. gonorrhoeae. N. gonorrhoeae has developed resistance to every class of currently available 
antibiotic [7]. The WHO lists $N$. gonorrhoeae as a "priority pathogen" for which new therapies are urgently needed [8]. The current recommended treatment by the WHO is dual therapy with ceftriaxone and azithromycin, although in many countries single-dose ceftriaxone or cefixime is used $[9,10]$. N. gonorrhoeae strains exhibiting resistance to both ceftriaxone and azithromycin have already been identifiied $[11,12]$. In light of this, it is essential to tailor currently available antimicrobial therapies, discover novel alternative treatments, and develop vaccines to curb both the high prevalence and growing resistance of $N$. gonorrhoeae. In this review, we will discuss the epidemiology of $N$. gonorrhoeae resistance globally, the current progress in new treatments, and vaccine development. All information has been gathered from relevant articles in PubMed under the search terms "Neisseria gonorrhoeae" and "antimicrobial resistance" or "epidemiology" or "treatment" or "vaccines" published from 2010 through November 27th, 2020.

\section{Timeline, Surveillance, and Epidemiology of Antimicrobial Resistance in $\mathbf{N}$. gonorrhoeae}

N. gonorrhoeae has an extraordinary ability to develop resistance mechanisms to antibiotics. Data on the evolution of antimicrobial resistance (AMR) show that prior to the modern use of antibiotics, $N$. gonorrhoeae did not harbor AMR elements and that resistance has been driven by the widespread use and misuse of antibiotics $[13,14]$. With the introduction of each new antibiotic, resistance soon followed: sulfonamides (1930s, 90\% resistance by 1940s), penicillins (1943, no longer recommended 1989), spectinomycin (1961, reported resistance rapidly emerge in 1987), tetracyclines (1962, high-level resistance reported in 1985), fluoroquinolones (1980s, no longer recommended in 2007), azithromycin (1983, no longer recommended in 2007), ceftriaxone (1980, first high-level resistance strain reported in 2009), cefixime (1983, clinical failures in Japan in 2010) [15-18]. Ceftriaxone is currently the final remaining empiric treatment option, highlighting the urgent need for research and development of new antibiotics.

There are several major efforts to monitor antimicrobial susceptibilities in countries worldwide. Country-specific surveillance programs for $N$. gonorrhoeae include the Gonococcal Isolate Surveillance Program (GISP) in the USA; the Gonococcal Resistance to Antimicrobial Surveillance (GRASP) in the UK; the Australian Gonococcal Surveillance Program (AGSP) in Australia; and recently, the Enhanced Surveillance of Antimicrobial-Resistant Gonorrhea (ESAG) in Canada [19, 20]. In Europe, members of the
European Union have a joint surveillance program called the European Gonococcal Antimicrobial Surveillance Program (Euro-GASP) [19]. Although each of those programs differ slightly from each other in terms of methodology, each provide data and analysis on the trends of antimicrobial susceptibilities for treatment guidelines [19]. The WHO established the Gonococcal Antimicrobial Surveillance Program (GASP) in 1992, with designated regional focal points collecting susceptibility data from participating countries, leading to informed regional and global treatment guidelines. However, only 77 countries reported data in 2014, and the number of countries reporting AMR data for at least one antibiotic each year has been declining [19]. Finally, there are several other countries still in development of their gonococcal AMR surveillance programs, while other countries lack any effort due to various limitations (e.g. laboratory capacity, funding, etc.). Implementing optimal surveillance programs globally is of utmost importance [5].

While there is an absence of data from many countries for $N$. gonorrhoeae, the proportion of countries reporting resistance to ciprofloxacin from 2014-2016 was 97-100\% and to azithromycin 81-83\% [21]. A recent analysis of global AMR surveillance data found the prevalence of $N$. gonorrhoeae with decreased susceptibility or resistance to extended-spectrum cephalosporins (e.g. ceftriaxone, cefixime) to be $\geq 5 \%$ in China, Greenland, Norway, India, Japan, South Korea, Indonesia, Denmark, Romania, Belgium, and Malaysia [22].

Although the data are limited, the trend by region for ceftriaxone resistance is generally as follows: (1) Europe: increasing prevalence of ceftriaxone decreased susceptibility (ceftriaxone-DS) about 15\% [23], (2) North America: low prevalence of ceftriaxone-DS, below $2 \%$ in both USA and Canada [24, 25], (3) Oceania: low rates of ceftriaxoneDS below 2\% in Australia [26, 27], (4) Asia: high rates of ceftriaxone-DS with 35.3\% (18/51) locations of the Western Pacific Region and South-East Asian Region reporting over 5\% prevalence of ceftriaxone-DS [28] notably with China around 10\% ceftriaxone-DS [29], (5) South America: although surveillance data are limited, the proportion of ceftriaxone-DS strains appears to be low based on the available country-specific data: all strains in published reports from Brazil and Peru were ceftriaxone susceptible [30, 31], (6) Africa: similarly, surveillance data on ceftriaxone-DS strains from Africa are limited. A recent review of published articles observed no ceftriaxone resistance (ceftriaxone-R), although AMR data were absent for $42.6 \%$ of countries in the African continent [32]. Case reports of specific nations suggest low rates of ceftriaxone-R; for example, $0.5-1.1 \%$ ceftriaxone-R in Uganda [33], $0.1 \%$ ceftriaxone- $R$ in South Africa [34], 0\% ceftriaxone-DS in Ethiopia [35, 36].

Overall, it appears there are overall low rates for ceftriaxone- $\mathrm{R}<5 \%$ in most countries. The prevalence of decreased 
susceptibility to ceftriaxone is also low in these countries, with the exception in certain Asian and European countries. Therefore, the dual therapy with ceftriaxone and azithromycin, as recommended by the WHO, remains sufficient for most settings [9].

There are strains identified to have high levels of resistance to ceftriaxone. Fortunately, those strains have mostly been sporadic [e.g. H041 in Japan (2009) [7], F89 in France (2010) [37], A8806 in Australia (2013) [38], and GU140106 in Japan (2014) [39]]. However, one ceftriaxone-R strain, FC428, has been identified in several countries including Australia [40], Canada [41], China [42-45], Denmark [40], Ireland [46], and Japan [40]. Moreover, strains of this clone have been identified with intermediate resistance to azithromycin $(2018)[12,46]$ and multidrug resistance (MDR) status (2019) [47]. Aside from FC428, a ceftriaxone-R clone deemed A2543 demonstrating high resistance to azithromycin has been found in both the UK and Australia [11].

While resistance to ceftriaxone and azithromycin is low, there are three goals that should be pursued in order to curb the spread of antimicrobial-resistant $N$. gonorrhoeae: (1) tailoring treatments to patient-specific $N$. gonorrhoeae strains, (2) developing novel treatments for gonorrhea, and (3) developing a vaccine for $N$. gonorrhoeae.

\section{Treatment of $N$. gonorrhoeae}

\subsection{Review of Current Treatment Recommendations}

Currently, dual-therapy with extended spectrum cephalosporins (ESCs), primarily injectable ceftriaxone, and azithromycin, is recommended for empiric treatment of gonorrhea by the WHO [9]. However, some countries have transitioned to ceftriaxone monotherapy [48]. In December 2020, the U.S. Centers for Disease Control and Prevention (CDC) removed azithromycin from the treatment recommendation due to the increasing incidence of azithromycin resistance and increased the recommended ceftriaxone dose from 250 to $500 \mathrm{mg}$ intramuscular injection [49], joining several other countries, including the UK, China, and Japan, in recommending higher doses of ceftriaxone as monotherapy for gonorrhea $[10,50,51]$.

Treatment failures with dual therapy have occurred. In 2014 and 2018, two cases of gonorrhea treatment failures associated with dual therapy were reported in the UK [52, 53]. Both infections were acquired in Asia and likely represent the tip of the iceberg, as surveillance of AMR and treatment failures are limited [54]. Treatment failures typically involve pharyngeal infections [55], which are an important site of infection, although they are predominantly asymptomatic and thus primarily detected through screening. Those reports of gonorrhea treatment failures to dual antibiotic therapy are dire warnings that the era of untreatable gonorrhea is near.

Public health measures also play an important role in the treatment and prevention of antimicrobial-resistant $N$. gonorrhoeae infections, and many were outlined in the WHO's Global Action Plan against AMR in N. gonorrhoeae [3]. A robust public health surveillance system that can rapidly detect drug-resistant gonococcal infections could allow for focused efforts related to outbreaks or clusters within the population. Improving diagnostics for AMR in $N$. gonorrhoeae would not only benefit the treatment of resistant infections but could also be used to identify those at higher risk for treatment failures and for whom follow-up testing for test-of-cure would be beneficial. In addition, improving the diagnosis of resistant infections could also allow for focused contacttracing efforts that could identify additional infections and mitigate the spread of resistant infections. Increasing knowledge, awareness, and advocacy of AMR in $N$. gonorrhoeae among clinicians, health officials, policy makers, and among the general population can play an important role in the treatment and prevention of drugresistant infections.

\subsection{Brief Overview of $\boldsymbol{N}$. gonorrhoeae Mechanisms of Antimicrobial Resistance}

$N$. gonorrhoeae exhibits several resistance mechanisms against antimicrobials. We will briefly review those related to cephalosporins, azithromycin, and fluoroquinolones, as these are the most common antibiotics used to treat gonococcal infections today.

There are four main genes that have been implicated in resistance to cephalosporins: penA, penB, $m t r R$, and ponA $[56,57]$. pen $A$ encodes the penicillin-binding protein 2 , and there are currently 83 specific amino acid positions where mutations are associated with decreased susceptibility to cephalosporins. pen $B$ (also known as porB1b) is an allele of por $B$ and encodes an outer membrane porin; amino acid alterations at the G120 and A121 site decrease permeability for antimicrobials. $m t r R$ encodes a transcriptional repressor of the $m t r$ gene locus, which encodes the MtrC-MtrDMtrE efflux pump. Deletion of an adenine residue from the 13-base pair inverted repeat within the promoter region leads to upregulation of the efflux pump with subsequent increase in efflux of antimicrobials. ponA encodes for penicillinbinding protein 1 , and the amino acid alteration L421P has been associated with increased resistance to cephalosporins, although to a smaller magnitude than amino acid alterations within penA.

Resistance to azithromycin in $N$. gonorrhoeae is also mediated by multiple mechanisms [57]. SNPs in the $23 \mathrm{~S}$ 
rRNA gene, particularly C2611T and A2059G, lead to decreased affinity of the 50S ribosomal subunit for azithromycin. The $m t r R$ gene also contributes to azithromycin resistance through the same mechanisms described above. The erm genes encode rRNA methylases that result in methylation of nucleotides targeted on the 23S rRNA by azithromycin. Upregulation of the MacAB and mef-encoded efflux pumps results in increased efflux of azithromycin and decreased susceptibility.

Lastly, resistance to fluoroquinolones in $N$. gonorrhoeae is mediated by the alterations in the $g y r A$ and $\operatorname{parC}$ genes [57]. The gene gyrA encodes the A subunit of DNA gyrase enzyme; gyrA SNPs including S91F, D95N, and D95G result in decreased binding of fluoroquinolones to DNA gyrase. parC SNPs including D86N, S88P, and E81K also result in decreased binding of fluoroquinolones, except to the topoisomerase IV enzyme.

\subsection{Tailoring Current Treatment of $\boldsymbol{N}$. gonorrhoeae}

Molecular testing for antibiotic susceptibility is an important method that can guide treatment decisions for $N$. gonorrhoeae, allowing for resistance-guided therapy. For example, molecular testing has allowed for the re-introduction of ciprofloxacin in the treatment of $N$. gonorrhoeae. Screening for a serine at amino acid position 91 in the gyrase A gene enables prediction of ciprofloxacin susceptibility and has led to the development of a commercial assay [58, 59]. Recently, a clinical study demonstrated promising results with $100 \%$ microbiological cure at all anatomic sites in 117 $N$. gonorrhoeae infections, reviving the use of ciprofloxacin in strains with wild type $S 91$ [60]. While this clinical study only included treatment of 14 pharyngeal infections, ciprofloxacin was historically highly effective in treating pharyngeal infections [61]. In light of these results, the 2018 UK national guideline for treatment of $N$. gonorrhoeae now recommends single-dose ciprofloxacin $500 \mathrm{mg}$ orally when ciprofloxacin susceptibility is known [10].

There has also been progress in predicting antimicrobial susceptibility to cefixime. Deng et al. previously detailed six codons that could be used to detect cefixime decreased susceptibility with $99.5 \%$ sensitivity [62]. Although an assay is currently in development, these alleles have correctly predicted 115/121 (95.9\%) N. gonorrhoeae strains with decreased susceptibility to cefixime [63]. As recommended by the WHO, cefixime is particularly useful in lowresistance areas, as it is widely available, safe in pregnancy, taken orally, and can be used in partner-expedited therapy [ 9 , 64]. Of note, the new 2020 US CDC guidelines recommend cefixime $800 \mathrm{mg}$ orally for partners [49].

Given the rise of $N$. gonorrhoeae strains resistant to ceftriaxone, the ability to rapidly predict susceptibility to ceftriaxone using a molecular assay could aid the diagnosis, treatment, and ultimately, reduce the transmission of resistant strains. A molecular assay could identify gonococcal infections requiring further antibiotic susceptibility testing or needing treatment with higher doses of ceftriaxone. Increasing ceftriaxone doses $(\geq 1000 \mathrm{mg}$ ) has been shown to be effective in treating $N$. gonorrhoeae strains with decreased susceptibility in China [65]. Assays to detect decreased susceptibility to ceftriaxone could also be used to identify patients requiring follow-up with a test of cure in order to detect treatment failures, decrease the need for repeat visits to clinic due to treatment failure, and potentially lower overall costs of treatment [64]. Moreover, having an assay to rapidly identify ceftriaxone resistance would be extremely beneficial as resistance to ceftriaxone remains low in most settings [22], and this might allow for alternative treatment approaches. However, the wide genetic heterogeneity and multiple mechanisms of resistance to ceftriaxone in $N$. gonorrhoeae make prediction difficult.

Currently, a universal molecular assay to predict ceftriaxone decreased susceptibility or resistance to $N$. gonorrhoeae does not exist. Prior studies have shown there are genetic markers predictive of resistance, but these are limited to specific geographic areas. Peterson et al. in 2015 reported a molecular assay to predict decreased susceptibility to cephalosporins, including ceftriaxone. The highest sensitivity and specificity reported was $98.3 \%$ and $66.7 \%$, respectively, achieved by screening alleles in penA, porB, pon $A$, and $m t r R$ [66], although the assay was constructed and validated amongst Canadian strains. Donà et al. developed a molecular algorithm to predict resistance to ESCs by screening two amino acid positions in penA, but is limited in its application to only two specific penA mosaic alleles and strains from Switzerland [67]. More recently, Peterson et al. reported a novel molecular assay predicting intermediateto-decreased susceptibility to ceftriaxone with a high sensitivity and specificity $99.8 \%$ and $89.0 \%$. However, a lower minimum inhibitory concentration (MIC) cutoff of 0.032 $\mathrm{mg} / \mathrm{L}$ was used as opposed to 0.063 , along with an overlap between susceptible (MICs $<0.125 \mathrm{mg} / \mathrm{L}$ ) and intermediate or decreased susceptible (MICs $\geq 0.032 \mathrm{mg} / \mathrm{L}$ ) [68]. Furthermore, when applied to a global genetic data set of $N$. gonorrhoeae isolates, sensitivity remained similar (98.4\%) but specificity decreased considerably to $67.3 \%$ [69].

Four preliminary molecular algorithms for predicting decreased susceptibility to ceftriaxone in $N$. gonorrhoeae using amino acid alterations penA, porB, $m t r R$, and ponA, presenting sensitivity and specificities up to $95 \%$ and $62 \%$, respectively, have been published [56]. That report was limited by incomplete genetic data for many strains, as the use of whole genome sequencing has only recently started to expand. Furthermore, the algorithms have proven successful in specific isolates [70], but have not yet been applied to larger sets of global isolates. Applying these algorithms to 
such sets and incorporating other genetic loci will enable verification of their validity and further improvement of their sensitivity and specificity values. The development of global molecular assays are critical, especially given the spread of multidrug-resistant gonorrhea strains internationally through international travel as evidenced with FC428 [40-45]. In these instances, using country-specific molecular assays would not be useful as they suffer from lower specificities. In addition, from a financial standpoint, a global molecular assay would be much more commercially viable. Therefore, it is critical for the continued expansion of $N$. gonorrhoeae surveillance, antimicrobial susceptibility testing, and wholegenome sequencing for the monitoring of genetic alterations attributed to resistance. With these efforts, a molecular assay can be developed that can help prevent $N$. gonorrhoeae treatment failure and slow the spread of resistant strains globally.

\subsection{Repurposing Antibiotics}

Another strategy for finding alternative treatments for $N$. gonorrhoeae includes repurposing antibiotics used in other infections. Sitafloxacin, a newer-generation broad-spectrum fluoroquinolone used for respiratory infections, has shown promise as a potential dual therapy candidate for gonorrhea $[71,72]$.

Aztreonam for treatment of $N$. gonorrhoeae has been studied for decades. A meta-analysis of 10 clinical trials of using aztreonam intramuscular (IM) or intravenous (IV) for uncomplicated gonococcal infections revealed that aztreonam was efficacious against urogenital and rectal infections with a $98.6 \%$ and $94.7 \%$ cure rate, respectively, and a limited activity for pharyngeal gonococcal infections with a $81.3 \%$ cure rate [73]. Most recently, a single-arm open-label clinical trial evaluating IM $2 \mathrm{~g}$ aztreonam for treatment of N. gonorrhoeae found similar findings with a 100\% (11/11) efficacy against urogenital infections, but lower efficacy in rectal $(75 \% ; 3 / 4)$ and pharyngeal infections $(33 \% ; 2 / 6)[74]$.

In contrast, effective treatment of extragenital $N$. gonorrhoeae infections was found in a randomized control trial comparing gentamicin and azithromycin dual therapy versus ceftriaxone and azithromycin dual therapy in pharyngeal and rectal infections, with $100 \%$ clearance in both treatments and similar rates of gastrointestinal adverse events, the majority of which were considered mild [75]. However, the same results were not observed in the G-ToG trial, a noninferiority trial comparing gentamicin and azithromycin to ceftriaxone and azithromycin for the treatment of gonorrhea. Clearance with gentamicin and azithromycin dual therapy was $94 \%$ (vs $98 \%$ in ceftriaxone/azithromycin) for genital infections, $90 \%$ (vs $98 \%$ ) for rectal infections, but $80 \%$ (vs $96 \%$ ) for pharyngeal infections [76]. For these reasons, gentamicin is not a first-line recommendation for treatment.
Several other antibiotics have shown promising in vitro studies in treating $N$. gonorrhoeae with similar or even superior antimicrobial activity in comparison to currently used antibiotics, including nitroxoline [77], salicylamide [78], mupirocin [79], fenamic acid derivatives [80], apramycin [81], and polyketides enacyloxin IIa and gladiolin [82]. Furthermore, several novel combinations of antibiotics including gentamicin with ertapenem, moxifloxacin with ertapenem, spectinomycin with ertapenem, azithromycin with moxifloxacin, and cefixime with gentamicin have been shown to have excellent in vitro activity against $N$. gonorrhoeae [83]. All of these promising candidates require further evaluation.

Of note, other drugs used for treatments outside of antimicrobials also warrant investigation. For example, Auranofin, a gold-containing drug used for rheumatoid arthritis, was shown to outperform ceftriaxone in reducing burden of intracellular N. gonorrhoeae (99\%), reducing secretion of IL-8 secretion, having prolonged post-antibiotic effects, and lacking an ability to generate resistant mutants [84]. Another example is with carbamazepine and methyldopa, an antiepileptic and anti-hypertensive drug. When used for cervical cell infection by MDR $N$. gonorrhoeae, prevention and cure was found via blocking of the I-domain of the gonococcal complement receptor 3 domain [85].

\subsection{Newer Agents for Treatment of $\boldsymbol{N}$. gonorrhoeae}

There are several promising agents on the horizon for $N$. gonorrhoeae. These include three novel antibiotics that have reached Phase III clinical trials.

\subsubsection{Zoliflodacin}

Zoliflodacin is a novel antibiotic in the unique class of spiropyrimidinetriones that works by targeting the GyrB subunit in DNA gyrase (DNA gyrase subunit B), stabilizing the cleaved covalent complex of DNA gyrase with double-strand broken DNA and preventing religation to form circular DNA [86-88]. Although zoliflodacin has a similar mechanism of action to ciprofloxacin, zoliflodacin does not utilize a $\mathrm{Mg}^{2+}$ ion as does ciprofloxacin [89]. Studies have also shown zoliflodacin to be effective in ciprofloxacin-resistant strains [90]. More generally, no cross-resistance has been demonstrated with any previously developed antimicrobials [86, 88, 89, 91, 92], making zoliflodacin ideal for any $N$. gonorrhoeae strain resistant to any currently used antibiotic. Up to now, no strains have been reported with resistance to zoliflodacin, although resistant mechanisms uncovered through in vitro studies suggest amino acid alterations D429N and K450N/T in the $G y r B$ to play significant roles in increasing MICs [93]. The role other genes play in zoliflodacin resistance remains to be uncovered [94]. 
Clinical studies on the efficacy of zoliflodacin have been promising. Beginning with in vitro studies, zoliflodacin exhibited rapid inhibition of growth against $N$. gonorrhoeae [95], demonstrating potent in vitro activity against "geographically, temporally, and genetically diverse" strains including those that are resistant to ceftriaxone [91]. Overall, zoliflodacin demonstrated a lower modal $\mathrm{MIC}, \mathrm{MIC}_{50}$, and $\mathrm{MIC}_{90}$ to every previously used antimicrobial except with regard to ceftriaxone, where all values were highly comparable [90-92].

A Phase II clinical trial using a single oral dose of 2 or 3 $\mathrm{g}$ for uncomplicated gonorrhea was completed in December 30,2015 in the USA [96]. Zoliflodacin doses of $2 \mathrm{~g}$ and 3 g exhibited $98 \%$ and $100 \%$ treatment success rates for urogenital gonorrhea, respectively, $100 \%$ for rectal gonorrhea, and $67 \%$ and $78 \%$ for pharyngeal gonorrhea [96]. While the treatment success rates are lower for pharyngeal gonorrhea, there were much fewer patients in this group: 6 and 9 patients received $2 \mathrm{~g}$ and $3 \mathrm{~g}$ zoliflodacin, respectively. In these instances, zoliflodacin was not as effective as ceftriaxone [96]. Aside from pharyngeal gonorrhea, zoliflodacin appears both effective and well tolerated, with a side effect profile primarily limited to transient gastrointestinal upset [96]. Zoliflodacin proceeded to a Phase III clinical trial in May 2019 (http://www.clinicaltrial.gov, NCT03959527). At the time of this writing, the study is still recruiting participants and has not posted any results. The completion date is estimated to be May 2021 [97].

\subsubsection{Solithromycin}

Solithromycin is a fourth-generation, broad-spectrum macrolide targeting prokaryotic ribosomal sites that was explored extensively in recent years. In vitro studies revealed superior antibiotic activity to currently used antibiotics (including ceftriaxone and azithromycin) on $246 \mathrm{~N}$. gonorrhoeae isolates including the two multidrug-resistant strains H041 and F89 [98]. This was followed with Phase 2 clinical trials using two oral doses of solithromycin, $1200 \mathrm{mg}$ and $1000 \mathrm{mg}$. With both doses on a total of 59 participants, a $100 \%$ efficacy was found in all three sites (genital, oral, rectal) [99]. Adverse effects were limited to mild dose-related gastrointestinal effects that did not limit therapy.

Despite these results, the SOLITAIRE-U Phase 3 clinical trial examining solithromycin $(1000 \mathrm{mg})$ versus ceftriaxone and azithromycin dual therapy on uncomplicated genital gonorrhea failed to show non-inferiority with a $4.0 \%$ lower difference in eradication rate ( $80 \%$ vs $84 \%$ ) [100]. Furthermore, the frequency of adverse events in the solithromycin group was higher (53\% vs 34\%), with the most common event being diarrhea (24\% vs $15 \%)$ and nausea $(21 \%$ vs $11 \%$ ) [100]. Despite these disappointing results, it is unclear from the trial whether the differences in results could have been fixed with dose adjustments, and whether the failures were not re-infections. Moreover, the small 4\% difference between groups could potentially be accounted for by the $8 \%$ of solithromycin patients having HIV-related immunosuppression [101]. Regardless, solithromycin requires further evaluation for potential as an alternative first-line treatment for $N$. gonorrhoeae.

\subsubsection{Gepotidacin}

Gepotidacin is also a novel antibiotic in the triazaacenaphthylene class that works by inhibiting bacterial DNA gyrase and topoisomerase IV via a mechanism that is different from previous antibiotics, including quinolones [102]. In vitro studies showed potent activity of gepotidacin against all $\mathrm{N}$. gonorrhoeae strains, including multidrug-resistant strains with MICs [102, 103]. No cross-resistance was found with any other antibiotic, although the ParC D86N mutation associated with fluoroquinolone resistance was associated with higher gepotidacin MICs [103]. A Phase II clinical trial evaluating single dose gepotidacin for treatment of uncomplicated urogenital gonorrhea in either 1500 or $3000 \mathrm{mg}$ doses showed 96\% (66/69) cure rate in urogenital, pharyngeal, and rectal sites [104]. The three failures were quinolone resistant with the presence of a ParC D86 substitution, one of which was a rectal infection and the other two were urogenital. No treatment-limiting adverse effects were found with either dose, with the most frequent being diarrhea (27\%), flatulence (23\%), and abdominal pain (15\%) [104]. With these promising results, gepotidacin began a Phase III clinical trial comparing oral gepotidacin versus IM ceftriaxone and azithromycin dual therapy for treatment of uncomplicated urogenital $N$. gonorrhoeae infections. The trial started in July 2019 and is currently recruiting participants, with an estimated completion date in September 2023 (https://clini caltrials.gov/, NCT04010539) [105].

\subsection{Antimicrobial Treatments in Early Development}

In addition to the promising results of novel antibiotics zoliflodacin, solithromycin, and gepotidacin, there are several other upcoming antibiotics in earlier stages of development. SMT-571, an oral antimicrobial with a unique mechanism of action targeting bacterial cell division, has displayed potent activity in vitro on $262 \mathrm{~N}$. gonorrhoeae strains, including multidrug-resistant strains, with MICs ranging from 0.064 to $0.125 \mathrm{mg} / \mathrm{L}$, with no cross resistance or correlation with respect to MICs of other agents [106]. DIS-73825 is another novel small molecule antibiotic with a novel mechanism of action involving electron transfer proteins in $N$. gonorrhoeae. When screened in vitro amongst multidrug-resistant $N$. gonorrhoeae strains, DIS-73825 was found to have greater potency than any other antimicrobial previously 
used, with extremely low MICs from $\leq 0.001$ to $0.004 \mathrm{mg} / \mathrm{L}$ [107]. Lefamulin is another novel antibiotic in the pleuromutilin class of antibiotics inhibiting bacterial translation via binding to the peptidyl transfer center of the bacterial ribosome [108]. In vitro studies have shown low cross-resistance and high efficacy against several $N$. gonorrhoeae strains including those resistant to fluoroquinolones, ceftriaxone, azithromycin, and MDR strains [108-110]. Aminoethyl spectinomycins are a new class of semisynthetic analogs of spectinomycin that have shown in vitro activity against drug-resistant $N$. gonorrhoeae [111]. Next, closthioamide is the first of the polythioamide class of bacterial DNA gyrase inhibitors that has no cross-resistance with other drugs and inhibited 98\% (146/149) of strains with MICs $\leq 0.125 \mathrm{mg} / \mathrm{L}$, making it another potential agent for drug-resistant $N$. gonorrhoeae [112]. Finally, tebipenem, the active metabolite of the oral carbapenem tebipenem pivoxil, has previously demonstrated potent activity against $N$. gonorrhoeae [113]. There have been few efforts to further study tebipenem in $N$. gonorrhoeae treatment, but efforts to investigate tebipenem for treatment of multidrug-resistant Gram-negative infections have recently been reignited $[114,115]$. All of these novel antibiotics could potentially serve as novel first-line agents in the treatment of $N$. gonorrhoeae. It is essential to begin further in vivo and clinical trial studies for these agents.

There are other novel antibiotics that are currently being explored for $N$. gonorrhoeae. Irrestin-16 is a novel antibiotic targeting both folate metabolism and disrupting bacterial membrane integrity that has shown efficacy against $N$. gonorrhoeae in a mouse vaginal infection model [116]. Cethromycin, a novel ketolide, displayed potent in vitro activity against multidrug-resistant strains of $N$. gonorrhoeae, although cross-resistance has been identified with azithromycin [117]. Phenelfamycin B is a natural product linear polyketide that targets the EF-Tu translation factor and has demonstrated potent in vitro activity against multidrug-resistant $N$. gonorrhoeae (MIC $\sim 1 \mu \mathrm{g} / \mathrm{mL}$ ) [118]. While all of these agents are in very preliminary stages of development in the treatment of gonorrhea, it is important to continue exploring their efficacy as AMR in N. gonorrhoeae continues to rise.

\subsection{Non-traditional Antibiotic Treatments}

There are several other treatments outside of small molecule antibiotics that are being investigated for use in $N$. gonorrhoeae, and we will highlight a few of them here. Closo-dodecaborate dianion fused with oxazoles is a $3 \mathrm{D}$ heterocycle that has exhibited strong, selective antimicrobial activity against $N$. gonorrhoeae [119]. Cell-penetrating peptides have also been investigated, showing 95-100\% killing of gonococcal strains tested with no cytotoxicity to human THP-1 cells [120]. MNBA-AgNCs are silver nanoclusters that have shown in vitro activity against $N$. gonorrhoeae superior to ceftriaxone and azithromycin with minimal toxicity to eukaryotic cells [121]. With respect to $N$. gonorrhoeae biofilms, antimicrobial blue light (aBL) has been found to preferentially inactivate $N$. gonorrhoeae over human vaginal epithelial cells in vitro, utilizing endogenous aBL-activatable photosensitizing porphyrins in N. gonorrhoeae [122]. Moreover, no genotoxicity to vaginal epithelial cells was identified, and no resistance to aBL treatment developed after 15 successive cycles of subtherapeutic exposure. Another therapy that has been of interest is utilizing bacteriophages to treat multidrug-resistant infections [123, 124]. However, the application of this potential therapy to $N$. gonorrhoeae is still in its early stages. Lastly, despite recent enthusiasm about topical bactericidal agents such as Listerine mouthwash, clinical studies on its treatment of oropharyngeal $N$. gonorrhoeae infections have been disappointing [125].

\subsection{Novel Targets for Future Antibiotics and Therapies}

Recent years in N. gonorrhoeae research has revealed several novel therapies that might have potential in the development of new treatments for gonorrhea. Some recent developments in therapeutics have been through the enhancement of host innate immunity by interfering with $N$. gonorrhoeae and host cell interactions. Samchenko et al. investigated the utilization of host mannosylated glycans on cervical and urethral epithelial cells by N. gonorrhoeae [126, 127]. Pretreatment of cells with a free mannose competitor or mannosespecific lectin reduced gonococcal adherence to epithelial cells [126]. Ragland et al. investigated mechanisms of inhibiting lysozyme activity, identifying two proteins employed by $N$. gonorrhoeae in order to fully neutralize host lysozyme activity, both of which can serve as potential targets for the development of new antimicrobial therapies [128]. Other bacterial targets with similar strategies are in Table 1.

Other investigators have focused on intrinsic mechanisms important for $N$. gonorrhoeae survival. One such mechanism is the outer-membrane bound TonB-dependent transporters (TdTs) that $N$. gonorrhoeae use for uptake of metalloproteins from hosts [129]. Kammerman et al. found that one specific TdT, $T d f H$, was found to be highly conserved in Neisseria species, making this an ideal target for antimicrobial therapy [129]. A separate highly conserved component of $N$. gonorrhoeae is a multicomponent protein complex (BAM) critical to the synthesis of $\beta$-barrel outer membrane proteins [130]. Specifically, Sikora et al. found that BamD is essential for $N$. gonorrhoeae viability, also making it an 
attractive antimicrobial target [130]. Other potential bacterial targets for antimicrobial therapy are listed in Table 1.

By developing treatments that can target and disrupt the activities of these aforementioned targets, facilitated eradication of multidrug-resistant $N$. gonorrhoeae infections can occur.

\section{Vaccine Development for N. gonorrhoeae}

As $N$. gonorrhoeae continues to develop resistance to antimicrobial treatments, development of a vaccine is critical. Mathematical modeling suggests that even with a vaccine with 7.5 years of protection and $100 \%$ efficacy or a vaccine with durable protection and $50 \%$ efficacy, gonococcal infections can be reduced up to $90 \%$ after 20 years if vaccination is administered in early adolescence
[131]. However, vaccine efforts in the past have been largely unsuccessful. In the 1970s, a crude, killed whole-cell vaccine was successful in developing an antibody response but failed to induce an adaptive immune response in clinical trials $[132,133]$. Another vaccine utilized the gonococcal pilin, but failed in a large field trial and heterologous challenge study, attributed to the antigenic variation of the pili [134-136]. A third unsuccessful attempt focused on the porin protein, also attributed due to genetic variation [134]. In general, vaccine development is impeded by the lack of natural acquired immunity that can be developed to $N$. gonorrhoeae due to its diverse antigenic variation and multiple mechanisms of immune evasion and its host restriction to humans [137, 138]. However, further elucidation of the mechanisms of $N$. gonorrhoea for evading the immune system, [139-143] humanized mouse models [144-147], and the

Table 1 Targets of interest for development of future antibiotics for treatment of Neisseria gonorrhoeae

\begin{tabular}{|c|c|c|c|}
\hline Target & Category & Therapeutic mechanism & Literature \\
\hline Host cell glycans & $\begin{array}{l}\text { N. gonorrhoeae-host cell interac- } \\
\text { tions }\end{array}$ & $\begin{array}{l}\text { Target glycans to block gonococcal } \\
\text { adherence to host cells }\end{array}$ & Semchenko et al. [126, 127] \\
\hline O-acetyltransferase $P a t B$ & $\begin{array}{l}\text { N. gonorrhoeae-host cell interac- } \\
\text { tions }\end{array}$ & $\begin{array}{l}\text { Inhibit O-acetyltransferase } P a t B \text { to } \\
\text { decrease resistance to lysozyme } \\
\text { and } \beta \text {-lactam antibiotics }\end{array}$ & Brott et al. [165] \\
\hline $\begin{array}{l}\text { N. gonorrhoeae lysozyme inhibitors } \\
\text { Ng_1063 and Ng_1981 }\end{array}$ & $\begin{array}{l}\text { N. gonorrhoeae-host cell interac- } \\
\text { tions }\end{array}$ & $\begin{array}{l}\text { Target any of two to prevent neutral- } \\
\text { ization of host lysozyme activity }\end{array}$ & Ragland et al. [128] \\
\hline $\mathrm{C} 4 \mathrm{~b}$ binding protein $(\mathrm{C} 4 \mathrm{BP})^{\mathrm{a}}$ & $\begin{array}{l}\text { N. gonorrhoeae - host cell interac- } \\
\text { tions }\end{array}$ & $\begin{array}{l}\text { Utilizing C4BP-IgM } \mathrm{M}^{\mathrm{b}} \text { to enhance } \\
\text { complement deposition }\end{array}$ & Bettoni et al. [166] \\
\hline N. gonorrhoeae lipooligosaccharides & $\begin{array}{l}\text { N. gonorrhoeae - host cell interac- } \\
\text { tions }\end{array}$ & $\begin{array}{l}\text { Utilize } \mathrm{CMP}^{\mathrm{c}} \text {-sialic acid analogues } \\
\text { to prevent resistance to comple- } \\
\text { ment }\end{array}$ & Gulati et al. [167] \\
\hline N. gonorrhoeae factor $\mathrm{H}$ domains & $\begin{array}{l}\text { N. gonorrhoeae-host cell interac- } \\
\text { tions }\end{array}$ & $\begin{array}{l}\text { Fusion protein of factor } \mathrm{H} \text { domains } \\
\text { and human } \mathrm{IgG} 1^{\mathrm{d}} \mathrm{Fc} \text { region to } \\
\text { enhance complement-dependent } \\
\text { killing }\end{array}$ & Shaughnessy et al. [168] \\
\hline $\begin{array}{l}\text { TonB-dependent transporter } \mathrm{H} \\
\text { (TdfH) }\end{array}$ & N. gonorrhoeae intrinsic mechanism & $\begin{array}{l}\text { Disrupt } N \text {. gonorrhoeae uptake of } \\
\text { necessary metalloproteins }\end{array}$ & Kammerman et al. [129] \\
\hline Non-human GADPH ${ }^{\mathrm{e}}$ & N. gonorrhoeae intrinsic mechanism & $\begin{array}{l}\text { Disrupt } N \text {. gonorrhoeae metabolism } \\
\text { (glycolysis) }\end{array}$ & Barrett et al. [169] \\
\hline Protein complex $\mathrm{BamD}$ & N. gonorrhoeae intrinsic mechanism & $\begin{array}{c}\text { BamD is essential for } N \text {. } \\
\text { gonorrhoeae viability }\end{array}$ & Sikora et al. [130] \\
\hline $\operatorname{LpxC}^{\mathrm{f}}$ & N. gonorrhoeae intrinsic mechanism & LpxC inhibitors & John et al. [170] \\
\hline $\begin{array}{l}\text { Mechanosensitive channel } \\
(\mathrm{Ng}-\mathrm{MscS})\end{array}$ & N. gonorrhoeae intrinsic mechanism & $\begin{array}{l}\text { Deletion led to impaired coloniza- } \\
\text { tion and survival }\end{array}$ & Wang et al. [171] \\
\hline$m t r C D E$ efflux pump operon & N. gonorrhoeae intrinsic mechanism & $\begin{array}{l}\text { Expression of wildtype copy of } \\
\text { repressor } m t r R \text { gene enhances } \\
\text { beta-lactam activity }\end{array}$ & Chen et al. [172] \\
\hline
\end{tabular}

${ }^{\mathrm{a}} \mathrm{C} 4 \mathrm{BP}(\mathrm{C} 4 \mathrm{~b}$ binding protein) is a complement inhibitor

${ }^{\mathrm{b}} \mathrm{IgM}$-Immunoglobulin M

${ }^{\mathrm{c}} \mathrm{CMP}$ - cytidine monophosphate

${ }^{\mathrm{d}} \mathrm{IgG}$-Immunoglobulin $\mathrm{G}$

${ }^{\mathrm{e}} \mathrm{GADPH}$ - glyceraldehyde-3-phosphate dehydrogenase

${ }^{\mathrm{f}} \mathrm{LpxC}$ is a deacetylase enzyme involved in Lipid A synthesis 
discovery of promising targets have reignited efforts for vaccine discovery.

\subsection{Current Efforts and Targets for N. gonorrhoeae Vaccine Discovery}

The first report of potential protective immunity against gonorrhea was from a case-control study by Petousis-Harris et al, involving the MeNZB vaccine against $N$. meningitidis in New Zealand. That study used reported gonorrhea cases in New Zealand from 2004 to 2016 and found that those who received the MenNZB vaccine had lower infection rates with an estimated vaccine effectiveness of $31 \%$ [148]. A subsequent retrospective cohort study by Paynter et al. found MeNZB to have a $24 \%$ effectiveness against hospitalizations due to gonococcal infections, providing support of the vaccine's cross-protectivity [149]. While the efficacy was low and dropped to $9 \%$ in 5 years [150], the durability is less of a concern because the risks of gonorrhea infections substantially decrease after age 30, making lifetime protection less important [151]. Other studies have also supported the potential protection of the meningococcal serogroup B vaccines against gonorrhea. Analyses of gonorrhea rates in Cuba and Norway both showed decreases in the incidence after their respective MenB vaccination campaigns $[152,153]$.

The MeNZB vaccine is no longer available, but a newer serogroup $B$ vaccine, $4 \mathrm{CMenB}$ called Bexsero, has the same outer membrane vesicle (OMV) components as in MeNZB, in addition to three recombinant proteins, of which Neisserial heparin binding antigen (NHBA), a target found to be important for gonococcal colonization and survival [127], is conserved and expressed on the surface of $N$. gonorrhoeae [154]. Not only has the vaccine successfully demonstrated anti-gonococcal antibodies induced by the OMVs, but it has also generated anti-gonococcal NHBA antibodies, putting forth another source of protection from $N$. gonorrhoeae [154]. These results have been further validated by mouse studies examining the cross-protection offered by the vaccine, in which accelerated clearance rates and reduced burden of $N$. gonorrhoeae have been found with antibodies recognizing several $N$. gonorrhoeae surface proteins including NHBA [155]. Bexsero is currently undergoing Phase II clinical trials (NCT04350138) with an estimated completion date in August 2023 [156].

There are also revived efforts to develop a wholecell-based vaccine for $N$. gonorrhoeae. Recently, Gala et al. developed a transdermal whole-cell-based inactivated gonococcal microparticle vaccine formulation [157]. The proposed advantages over prior vaccines and other wholecell preparations are (1) the use of formalin-fixed whole gonococci, protecting all immunogenic epitopes from degradation, and (2) the use of microparticles, which mimic the shape of the $N$. gonorrhoeae cocci shape, thereby activating the immune system without suppressing it, and (3) transdermal administration using microneedles enabling slow, sustained release of antigens to enhance their uptake [157]. Thus far, the vaccine has only been evaluated in vitro and in vivo mouse models, in which a significant increase in antigen-specific IgG titers was observed [157]. Further optimization and evaluation of whether this vaccine can provide immunity to challenge with the isogenic vaccine strain, along with cross-protection against various $N$. gonorrhoeae strains are required.

Moreover, there are efforts in the development of alternative methods of antigen presentation for vaccination. Gala et al, as described above, utilized microparticles to mimic cocci shape [157]. Jiao et al. designed a N. gonorrhoeae DNA vaccine delivered by Salmonella enteritidis bacterial ghosts, which are empty bacterial cell envelopes [158]. Bacterial ghosts enabled excellent DNA loading capacity with delivery to both professional and non-professional APCs, resulting in higher levels of $N$. gonorrhoeae PorB-specific serum antibodies than without ghosts in mice [158]. Wang et al. are working to employ Helicobacter pylori ferritin nanoparticles to present $N$. gonorrhoeae antigens for vaccine development [159]. This presenting system has been successfully demonstrated by Kanekiyo et al. with the Influenza and Epstein-Barr virus, resulting in more robust immune responses and protection against the viruses [160, 161].

In addition to the OMVs and NHBA described above, there are many other potential vaccine targets. In general, an ideal target would be one that is highly conserved among $N$. gonorrhoeae strains. First, many of the above targets in $N$. gonorrhoeae for novel antimicrobial therapy have also been suggested as potential candidates as vaccine targets (Table 1), such as the proteins $N$. gonorrhoeae use for complement evasion, nutrient uptake, protein synthesis machinery, lysozyme inactivation, and host-glycan binding. For example, one protein of the aforementioned $\beta$-barrel outer membrane complex, BamA, has been shown to be ubiquitously expressed under different growth conditions and elicit antibodies that cross-reacted with several diverse $N$. gonorrhoeae strains [162]. Zielke et al. also demonstrated that depletion of BamA resulted in loss of strain viability. Further research on these targets should be prioritized to facilitate development with respect to both treatment and vaccine.

Regardless, there are several other promising targets for vaccination as well (Table 2). For example, another target of interest is the lipooligosaccharide (LOS)-derived epitope $2 \mathrm{C} 7$. Although in general LOS widely varies by phase variation, $2 \mathrm{C} 7$ is a broadly expressed virulence determinant that has been found to be critical for gonococcal colonization in the experimental setting [163]. Gulati et al., who immunized 
mice with a peptide mimic of $2 \mathrm{C} 7$, found cross-reactive $\operatorname{IgG}$ antibodies with complement-dependent bactericidal activity that resulted in faster clearance of vaginal colonization and lower gonococcal burdens [163]. Based on this prototype peptide mimic vaccine, Gulati et al. have developed a tetrapeptide derivative in order to generate a homogeneous and stable vaccine candidate TMCP2 [164]. When evaluated with two different $N$. gonorrhoeae strains in mice, TMCP2 resulted in bactericidal IgG with reduced colonization levels and accelerated clearance, making TMCP 2 a promising step forward towards an effective $N$. gonorrhoeae vaccine [164]. Other vaccine targets are listed in Table 2. As more efforts for a $N$. gonorrhoeae vaccine are revived, the recent elucidation of these novel targets and $N$. gonorrhoeae's biological mechanisms of survival provide hope for a successful vaccine.

\section{Conclusion}

In this review, we covered the current status of antimicrobial-resistance in N. gonorrhoeae globally, discussed the importance of tailoring currently used antimicrobial treatments, and reviewed the progress of the development of novel treatments and vaccines. Antimicrobial resistance in $N$. gonorrhoeae is rising globally. Although prevalence of resistance and decreased susceptibility to ceftriaxone, the most-widely used first-line treatment, is low, the identification of strains with high resistance to ceftriaxone highlight the need for urgent action. Expanded global surveillance of AMR in N. gonorrhoeae is surely needed. In addition, the development of molecular assays to predict ceftriaxone resistance could improve detection and treatment of these infections. Approaches including the re-purposing of antibiotics could reduce our reliance on ceftriaxone. The number of antibiotic treatments for $N$. gonorrhoeae is extremely limited and there are few potential candidates in development, including zoliflodacin and gepotidacin, both of which are in Phase III clinical trials. There are novel agents in the early stages of investigation, but it will likely be several years before they reach clinical trials, if at all. In addition, efforts to develop vaccines have recently been revived with different modalities of delivery and utilization of highly-conserved surface components of $N$. gonorrhoeae strains. We have highlighted a few of these targets and summarized their preclinical success as in eliciting robust immune responses and effective clearance of $N$. gonorrhoeae. Overall, significant progress has been made towards combatting the spread of $N$. gonorrhoeae, but there is still significant work to be done towards effectively countering $N$. gonorrhoeae as a global health threat.

Table 2 Targets of interest for Neisseria gonorrhoeae vaccine development

\begin{tabular}{|c|c|c|}
\hline Target & Rationale/progress & Literature \\
\hline $\begin{array}{l}\text { Six gonococcal proteins expressed during human } \\
\text { mucosal infection }\end{array}$ & $\begin{array}{l}\text { Antibody-generation with bactericidal activity against } \\
N \text {. gonorrhoeae in mice }\end{array}$ & Zhu et al. [173] \\
\hline L-methionine binding lipoprotein MetQ & $\begin{array}{l}\text { Displayed on surface of } \sim 97 \% \text { N. gonorrhoeae world- } \\
\text { wide, with promising results in mice }\end{array}$ & Sikora et al. [174] \\
\hline Lipooligosaccharide-derived epitope $2 \mathrm{C} 7$ & $\begin{array}{l}\text { 2C7 is broadly expressed amongst } N \text {. gonorrhoeae } \\
\text { and is critical for gonococcal infection. Tetrapeptide } \\
\text { derivative of derivative vaccine TMCP2 developed }\end{array}$ & Gulati et al. $[163,164]$ \\
\hline MtrE protein and its Surface-expressed loop “Loop 2" & $\begin{array}{l}\text { MtrE is part of the MtrCDE multidrug transporter } \\
\text { system. Generated MtrE-dependent bactericidal } \\
\text { activity when used to immunize mice }\end{array}$ & Wang et al. [175] \\
\hline $\begin{array}{l}\text { Neisseria gonorrhoeae adhesin complex protein } \\
(\mathrm{Ng}-\mathrm{ACP})\end{array}$ & $\begin{array}{l}\text { Rabbit antiserum to recombinant } \mathrm{Ng}-\mathrm{ACP} \text { prevented } \\
\text { inhibition of human lysozyme w/100\% efficacy }\end{array}$ & Almonacid-Mendoza et al. [176] \\
\hline $\begin{array}{l}\text { Recombinant truncated } N \text {. meningitidis macrophage } \\
\text { infectivity potentiator protein (rT-Nm-MIIP) }\end{array}$ & $\begin{array}{l}\text { rT-Nm-MIIP induced cross-reactive antibodies with } \\
\text { bactericidal activity against certain } N \text {. gonorrhoeae } \\
\text { strains in mice }\end{array}$ & Humbert et al. [177] \\
\hline Transferrin binding proteins $\mathrm{A}$ and $\mathrm{B}$ (tbpA and tbpB) & $\begin{array}{l}\text { Both are ubiquitously expressed and induced systemic } \\
\text { vaginal antibodies in mice, though weak immune } \\
\text { response and negligible role in survival }\end{array}$ & Price et al. [178, 179] \\
\hline Nitrite reductase AniA & $\begin{array}{l}\text { Outer membrane glycoprotein essential for growth } \\
\text { and survival under } \mathrm{O}_{2} \text {-limited conditions }\end{array}$ & Shewell et al. [180] \\
\hline Outer membrane porin protein B (PorB) & $\begin{array}{l}\text { Highly conserved and of interest but has failed to } \\
\text { show promising results in vaccine development. } \\
\text { Correlates with protection with Th1 response but } \\
\text { not antibody response }\end{array}$ & Zhu et al. [181] \\
\hline
\end{tabular}




\section{Declarations}

Funding This work was supported by the National Institutes of Health [R21 AI157817 to JDK and T32MH080634 to PCA].

Conflict of interest The authors have no conflicts of interest to declare.

Ethics approval Not applicable.

Consent to participate Not applicable.

Consent for publication Not applicable.

Availability of data and material Not applicable.

Code availability Not applicable.

Author contributions All authors (E.Y.L., P.C.A., J.D.K.) significantly contributed to the research and writing of this manuscript.

Open Access This article is licensed under a Creative Commons Attribution-NonCommercial 4.0 International License, which permits any non-commercial use, sharing, adaptation, distribution and reproduction in any medium or format, as long as you give appropriate credit to the original author(s) and the source, provide a link to the Creative Commons licence, and indicate if changes were made. The images or other third party material in this article are included in the article's Creative Commons licence, unless indicated otherwise in a credit line to the material. If material is not included in the article's Creative Commons licence and your intended use is not permitted by statutory regulation or exceeds the permitted use, you will need to obtain permission directly from the copyright holder. To view a copy of this licence, visit http://creativecommons.org/licenses/by-nc/4.0/.

\section{References}

1. Unemo M, Seifert HS, Hook EW 3rd, Hawkes S, Ndowa F, Dillon JR. Gonorrhoea. Nat Rev Dis Primers. 2019;5(1):79. https:// doi.org/10.1038/s41572-019-0128-6.

2. Keshvani N, Gupta A, Incze MA. I am worried about gonorrhea: what do i need to know? JAMA Intern Med. 2019;179(1):132. https://doi.org/10.1001/jamainternmed.2018.4345.

3. World Health Organization. Global action plan to control the spread and impact of antimicrobial resistance in Neisseria gonorrhoeae. Geneva: World Health Organization; 2012. https://www. who.int/reproductivehealth/publications/rtis/9789241503501/en/.

4. World Health Organization. Report on global sexually transmitted infection surveillance, 2018. Geneva: Switzerland; 2018.

5. Rowley J, Vander Hoorn S, Korenromp E, Low N, Unemo M, Abu-Raddad LJ, et al. Chlamydia, gonorrhoea, trichomoniasis and syphilis: global prevalence and incidence estimates, 2016. Bull World Health Organ. 2019;97(8):548-62. https://doi.org/10. 2471/blt.18.228486.

6. Newman L, Rowley J, Vander Hoorn S, Wijesooriya NS, Unemo $\mathrm{M}$, Low N, et al. Global estimates of the prevalence and incidence of four curable sexually transmitted infections in 2012 based on systematic review and global reporting. PLoS ONE. 2015;10(12):e0143304. https://doi.org/10.1371/journal.pone. 0143304.

7. Ohnishi M, Golparian D, Shimuta K, Saika T, Hoshina S, Iwasaku K, et al. Is Neisseria gonorrhoeae initiating a future era of untreatable gonorrhea?: detailed characterization of the first strain with high-level resistance to ceftriaxone. Antimicrob Agents Chemother. 2011;55(7):3538-45. https://doi.org/10.1128/ aac.00325-11.

8. Tacconelli E, Carrara E, Savoldi A, Harbarth S, Mendelson M, Monnet DL, et al. Discovery, research, and development of new antibiotics: the WHO priority list of antibiotic-resistant bacteria and tuberculosis. Lancet Infect Dis. 2018;18(3):318-27. https:// doi.org/10.1016/s1473-3099(17)30753-3.

9. World Health Organization. WHO guidelines for the treatment of Neisseria gonorrhoeae. Geneva: World Health Organization; 2016. https://apps.who.int/iris/handle/10665/246114.

10. Fifer H, Saunders J, Soni S, Sadiq ST, FitzGerald M. 2018 UK national guideline for the management of infection with Neisseria gonorrhoeae. Int J STD AIDS. 2020;31(1):4-15. https:// doi.org/10.1177/0956462419886775.

11. Jennison AV, Whiley D, Lahra MM, Graham RM, Cole MJ, Hughes G, et al. Genetic relatedness of ceftriaxone-resistant and high-level azithromycin resistant Neisseria gonorrhoeae cases, United Kingdom and Australia, February to April 2018. Euro Surveill. 2019. https://doi.org/10.2807/1560-7917.Es.2019.24.8. 1900118.

12. Eyre DW, Town K, Street T, Barker L, Sanderson N, Cole MJ, et al. Detection in the United Kingdom of the Neisseria gonorrhoeae FC428 clone, with ceftriaxone resistance and intermediate resistance to azithromycin, October to December 2018. Euro Surveill. 2019. https://doi.org/10.2807/1560-7917.Es.2019.24. 10.1900147.

13. Golparian D, Harris SR, Sánchez-Busó L, Hoffmann S, Shafer WM, Bentley SD, et al. Genomic evolution of Neisseria gonorrhoeae since the preantibiotic era (1928-2013): antimicrobial use/misuse selects for resistance and drives evolution. BMC Genom. 2020;21(1):116. https://doi.org/10.1186/ s12864-020-6511-6.

14. Sánchez-Busó L, Golparian D, Corander J, Grad YH, Ohnishi M, Flemming R, et al. The impact of antimicrobials on gonococcal evolution. Nat Microbiol. 2019;4(11):1941-50. https://doi.org/ 10.1038/s41564-019-0501-y.

15. Unemo M, Shafer WM. Antimicrobial resistance in Neisseria gonorrhoeae in the 21st century: past, evolution, and future. Clin Microbiol Rev. 2014;27(3):587-613. https://doi.org/10.1128/ cmr.00010-14.

16. Suay-García B, Pérez-Gracia MT. Future prospects for Neisseria gonorrhoeae treatment. Antibiotics (Basel). 2018. https://doi.org/ 10.3390/antibiotics7020049.

17. Unemo M, Del Rio C, Shafer WM. Antimicrobial resistance expressed by Neisseria gonorrhoeae: a major global public health problem in the 21 st century. Microbiol Spectr. 2016. https://doi.org/10.1128/microbiolspec.EI10-0009-2015.

18. Unemo M, Shafer WM. Antibiotic resistance in Neisseria gonorrhoeae: origin, evolution, and lessons learned for the future. Ann N Y Acad Sci. 2011;1230:E19-28. https://doi.org/10.1111/j. 1749-6632.2011.06215.x.

19. Weston EJ, Wi T, Papp J. Strengthening global surveillance for antimicrobial drug-resistant Neisseria gonorrhoeae through the enhanced gonococcal antimicrobial surveillance program. Emerg Infect Dis. 2017;23(13):S47-52. https://doi.org/10.3201/eid2313. 170443.

20. Public Health Agency of Canada. Report of the Enhanced Surveillance of Antimicrobial-Resistance Gonorrhea (ESAG). Ottawa: Public Health Agency of Canada; 2019.

21. Seña AC, Bachmann L, Johnston C, Wi T, Workowski K, Hook EW 3rd, et al. Optimising treatments for sexually transmitted infections: surveillance, pharmacokinetics and pharmacodynamics, therapeutic strategies, and molecular resistance prediction. Lancet Infect Dis. 2020;20(8):e181-91. https://doi.org/10.1016/ s1473-3099(20)30171-7. 
22. Wi T, Lahra MM, Ndowa F, Bala M, Dillon JR, Ramon-Pardo P, et al. Antimicrobial resistance in Neisseria gonorrhoeae: global surveillance and a call for international collaborative action. PLoS Med. 2017;14(7):e1002344. https://doi.org/10.1371/journ al.pmed.1002344.

23. Day MJ, Spiteri G, Jacobsson S, Woodford N, Amato-Gauci AJ, Cole MJ, et al. Stably high azithromycin resistance and decreasing ceftriaxone susceptibility in Neisseria gonorrhoeae in 25 European countries, 2016. BMC Infect Dis. 2018;18(1):609. https://doi.org/10.1186/s12879-018-3528-4.

24. Centers for Disease Control and Prevention. Sexually Transmitted Disease Surveillance 2018: Gonococcal Isolate Surveillance Project (GISP) Supplement and Profiles. Atlanta: U.S. Department of Health and Human Services; 2020.

25. Public Health Agency of Canada. Report on the enhanced surveillance of antimicrobial-resistant gonorrhea (ESAG)—results from 2014 and 2015. Ottawa: Public Health Agency of Canada; 2019. p. 2019.

26. Lahra MM, Enriquez RP, George CRR. Australian Gonococcal Surveillance Programme, 1 July to 30 September 2018. Commun Dis Intell. 2018;2019:43. https://doi.org/10.33321/cdi.2019.43.19.

27. Lahra MM, Hogan TR. Australian Gonococcal Surveillance Programme, 1 April to 30 June 2019. Commun Dis Intell. 2018;2020:44. https://doi.org/10.33321/cdi.2020.44.37.

28. George CRR, Enriquez RP, Gatus BJ, Whiley DM, Lo YR, Ishikawa N, et al. Systematic review and survey of Neisseria gonorrhoeae ceftriaxone and azithromycin susceptibility data in the Asia Pacific, 2011 to 2016. PLoS ONE. 2019;14(4):e0213312. https://doi.org/10.1371/journal.pone.0213312.

29. Yin YP, Han Y, Dai XQ, Zheng HP, Chen SC, Zhu BY, et al. Susceptibility of Neisseria gonorrhoeae to azithromycin and ceftriaxone in China: a retrospective study of national surveillance data from 2013 to 2016. PLoS Med. 2018;15(2):e1002499. https://doi.org/10.1371/journal.pmed.1002499.

30. Bazzo ML, Golfetto L, Gaspar PC, Pires AF, Ramos MC, Franchini M, et al. First nationwide antimicrobial susceptibility surveillance for Neisseria gonorrhoeae in Brazil, 2015-16. J Antimicrob Chemother. 2018;73(7):1854-61. https://doi.org/10.1093/ jac/dky090.

31. Jorge-Berrocal A, Mayta-Barrios M, Fiestas-Solórzano V. Antimicrobial resistance of Neisseria gonorrhoeae in Peru. Rev Peru Med Exp Salud Publica. 2018;35(1):155-6. https://doi.org/10. 17843/rpmesp.2018.351.3552.

32. Tadesse BT, Ashley EA, Ongarello S, Havumaki J, Wijegoonewardena M, González IJ, et al. Antimicrobial resistance in Africa: a systematic review. BMC Infect Dis. 2017;17(1):616. https://doi.org/10.1186/s12879-017-2713-1.

33. Workneh M, Hamill MM, Kakooza F, Mande E, Wagner J, Mbabazi O, et al. Antimicrobial resistance of Neisseria Gonorrhoeae in a newly implemented surveillance program in Uganda: surveillance report. JMIR Public Health Surveill. 2020;6(2):e17009. https://doi.org/10.2196/17009.

34. Kularatne R, Maseko V, Gumede L, Kufa T. Trends in Neisseria gonorrhoeae antimicrobial resistance over a ten-year surveillance period, Johannesburg, South Africa, 2008-2017. Antibiotics (Basel). 2018. https://doi.org/10.3390/antibiotics7030058.

35. Sahile A, Teshager L, Fekadie M, Gashaw M. Prevalence and antimicrobial susceptibility patterns of Neisseria gonorrhoeae among suspected patients attending private clinics in Jimma. Ethiopia Int J Microbiol. 2020;2020:7672024. https://doi.org/ 10.1155/2020/7672024.

36. Fentaw S, Abubeker R, Asamene N, Assefa M, Bekele Y, Tigabu E. Antimicrobial susceptibility profile of Gonococcal isolates obtained from men presenting with urethral discharge in Addis Ababa, Ethiopia: implications for national syndromic treatment guideline. PLoS ONE. 2020;15(6):e0233753. https://doi.org/10. 1371/journal.pone.0233753.

37. Unemo M, Golparian D, Nicholas R, Ohnishi M, Gallay A, Sednaoui P. High-level cefixime- and ceftriaxone-resistant Neisseria gonorrhoeae in France: novel penA mosaic allele in a successful international clone causes treatment failure. Antimicrob Agents Chemother. 2012;56(3):1273-80. https://doi.org/10.1128/aac. 05760-11.

38. Lahra MM, Ryder N, Whiley DM. A new multidrug-resistant strain of Neisseria gonorrhoeae in Australia. N Engl J Med. 2014;371(19):1850-1. https://doi.org/10.1056/NEJMc1408109.

39. Deguchi T, Yasuda M, Hatazaki K, Kameyama K, Horie K, Kato T, et al. New clinical strain of Neisseria gonorrhoeae with decreased susceptibility to ceftriaxone, Japan. Emerg Infect Dis. 2016;22(1):142-4. https://doi.org/10.3201/eid2201.150868.

40. Lahra MM, Martin I, Demczuk W, Jennison AV, Lee KI, Nakayama SI, et al. Cooperative recognition of internationally disseminated ceftriaxone-resistant Neisseria gonorrhoeae strain. Emerg Infect Dis. 2018;24(4):735-40. https://doi.org/10.3201/eid2404. 171873.

41. Berenger BM, Demczuk W, Gratrix J, Pabbaraju K, Smyczek P, Martin I. Genetic characterization and enhanced surveillance of ceftriaxone-resistant Neisseria gonorrhoeae strain, Alberta, Canada, 2018. Emerg Infect Dis. 2019;25(9):1660-7. https://doi. org/10.3201/eid2509.190407.

42. Chen SC, Han Y, Yuan LF, Zhu XY, Yin YP. Identification of internationally disseminated ceftriaxone-resistant Neisseria gonorrhoeae strain FC428, China. Emerg Infect Dis. 2019;25(7):1427-9. https://doi.org/10.3201/eid2507.190172.

43. Yang F, Zhang H, Chen Y, Zhai Y, Zhao F, Yu Y, et al. Detection and analysis of two cases of the internationally spreading ceftriaxone-resistant Neisseria gonorrhoeae FC428 clone in China. J Antimicrob Chemother. 2019;74(12):3635-6. https://doi.org/10. 1093/jac/dkz384.

44. Wang H, Wang Y, Yong G, Li X, Yu L, Ma S, et al. Emergence and genomic characterization of the ceftriaxone-resistant Neisseria gonorrhoeae FC428 clone in Chengdu, China. J Antimicrob Chemother. 2020;75(9):2495-8. https://doi.org/10.1093/jac/ dkaa123.

45. Chen SC, Yuan LF, Zhu XY, van der Veen S, Yin YP. Sustained transmission of the ceftriaxone-resistant Neisseria gonorrhoeae FC428 clone in China. J Antimicrob Chemother. 2020;75(9):2499-502. https://doi.org/10.1093/jac/dkaa196.

46. Golparian D, Rose L, Lynam A, Mohamed A, Bercot B, Ohnishi M, et al. Multidrug-resistant Neisseria gonorrhoeae isolate, belonging to the internationally spreading Japanese FC428 clone, with ceftriaxone resistance and intermediate resistance to azithromycin, Ireland, August 2018. Euro Surveill. 2018. https:// doi.org/10.2807/1560-7917.Es.2018.23.47.1800617.

47. Poncin T, Merimeche M, Braille A, Mainardis M, Bebear C, Jacquier H, et al. Two cases of multidrug-resistant Neisseria gonorrhoeae related to travel in south-eastern Asia, France, June 2019. Euro Surveill. 2019. https://doi.org/10.2807/15607917.Es.2019.24.36.1900528.

48. Unemo M, Seifert HS, Hook EW, Hawkes S, Ndowa F, Dillon J-AR. Gonorrhoea. Nat Rev Dis Primers. 2019;5(1):79. https:// doi.org/10.1038/s41572-019-0128-6.

49. St. Cyr S, Barbee L, Workowski KA, Bachmann LH, Pham C, Schlanger K, et al. Update to CDC's treatment guidelines for gonococcal infection, 2020. MMWR Morbidity Mortality Weekly Report. 2020;69(50):1911-6. https://doi.org/10.15585/ mmwr.mm6950a6.

50. Wang Q-Q, Zhang R-L, Liu Q-Z, Xu J-H, Su X-H, Yin Y-P, et al. National guidelines on diagnosis and treatment of gonorrhea in China. Int J Dermatol Venereol. 2020;3(3):129-34. https://doi.org/10.1097/JD9.0000000000000072. 
51. Matsumoto T. Guidelines on the diagnosis and treatment of sexually transmitted diseases. Nihon Rinsho. 2009;67(1):23-9.

52. Fifer H, Natarajan U, Jones L, Alexander S, Hughes G, Golparian D, et al. Failure of dual antimicrobial therapy in treatment of gonorrhea. N Engl J Med. 2016;374(25):2504-6. https://doi. org/10.1056/NEJMc1512757.

53. Eyre DW, Sanderson ND, Lord E, Regisford-Reimmer N, Chau $\mathrm{K}$, Barker L, et al. Gonorrhoea treatment failure caused by a Neisseria gonorrhoeae strain with combined ceftriaxone and high-level azithromycin resistance, England, February 2018. Eurosurveillance. 2018. https://doi.org/10.2807/1560-7917.es. 2018.23.27.1800323.

54. Unemo M, Jensen JS. Antimicrobial-resistant sexually transmitted infections: gonorrhoea and Mycoplasma genitalium. Nat Rev Urol. 2017;14(3):139-52. https://doi.org/10.1038/nrurol. 2016.268.

55. Unemo M, Lahra MM, Cole M, Galarza P, Ndowa F, Martin I, et al. World Health Organization Global Gonococcal Antimicrobial Surveillance Program (WHO GASP): review of new data and evidence to inform international collaborative actions and research efforts. Sex Health. 2019;16(5):412-25. https:// doi.org/10.1071/sh19023.

56. Lin EY, Adamson PC, Deng X, Klausner JD. Establishing novel molecular algorithms to predict decreased susceptibility to ceftriaxone in Neisseria gonorrhoeae strains. J Infect Dis. 2020. https://doi.org/10.1093/infdis/jiaa495.

57. Unemo M, Golparian D, Eyre DW. Antimicrobial resistance in Neisseria gonorrhoeae and treatment of gonorrhea. In: Christodoulides M, editor. Neisseria gonorrhoeae: methods and protocols. New York: Springer New York; 2019. p. 37-58.

58. Siedner MJ, Pandori M, Castro L, Barry P, Whittington WL, Liska S, et al. Real-time PCR assay for detection of quinoloneresistant Neisseria gonorrhoeae in urine samples. J Clin Microbiol. 2007;45(4):1250-4. https://doi.org/10.1128/jcm. 01909-06.

59. Hemarajata P, Yang S, Soge OO, Humphries RM, Klausner JD. Performance and verification of a real-time PCR assay targeting the gyrA gene for prediction of ciprofloxacin resistance in Neisseria gonorrhoeae. J Clin Microbiol. 2016;54(3):805-8. https:// doi.org/10.1128/jcm.03032-15.

60. Klausner JD, Bristow CC, Soge OO, Shahkolahi A, Waymer T, Bolan RK, et al. Resistance-guided treatment of gonorrhea: a prospective clinical study. Clin Infect Dis. 2020. https://doi.org/ 10.1093/cid/ciaa596.

61. Chaudry AE, Klausner JD. A Narrative review of clinical treatment outcomes of Neisseria gonorrhoeae infection with ciprofloxacin by minimum inhibitory concentration and anatomic site. Sex Transm Dis. 2021;48(6):385-92. https://doi.org/10.1097/olq. 0000000000001334.

62. Deng X, Allan-Blitz L-T, Klausner JD. Using the genetic characteristics of Neisseria gonorrhoeae strains with decreased susceptibility to cefixime to develop a molecular assay to predict cefixime susceptibility. Sex Health. 2019. https://doi.org/10. 1071/SH18227.

63. Deng X, Klausner JD. Six penA codons accurately and reliably predict cefixime-decreased susceptibility in Neisseria gonorrhoeae. J Infect Dis. 2019;221(5):851-2. https://doi.org/10.1093/ infdis/jiz504.

64. Golden MR, Whittington WL, Handsfield HH, Hughes JP, Stamm WE, Hogben M, et al. Effect of expedited treatment of sex partners on recurrent or persistent gonorrhea or chlamydial infection. N Engl J Med. 2005;352(7):676-85. https://doi.org/10. 1056/NEJMoa041681.

65. Han Y, Yin Y, Dai X, Chen S, Yang L, Zhu B, et al. Widespread use of high-dose ceftriaxone therapy for uncomplicated gonorrhea without reported ceftriaxone treatment failure: results from 5 years of multicenter surveillance data in China. Clin Infect Dis. 2020;70(1):99-105. https://doi.org/10.1093/cid/ ciz170.

66. Peterson SW, Martin I, Demczuk W, Bharat A, Hoang L, Wylie $\mathrm{J}$, et al. Molecular assay for detection of genetic markers associated with decreased susceptibility to cephalosporins in Neisseria gonorrhoeae. J Clin Microbiol. 2015;53(7):2042-8. https://doi. org/10.1128/jcm.00493-15.

67. Donà V, Smid JH, Kasraian S, Egli-Gany D, Dost F, Imeri F, et al. Mismatch amplification mutation assay-based real-time PCR for rapid detection of Neisseria gonorrhoeae and antimicrobial resistance determinants in clinical specimens. J Clin Microbiol. 2018. https://doi.org/10.1128/jcm.00365-18.

68. Peterson SW, Martin I, Demczuk W, Barairo N, Naidu P, Lefebvre B, et al. Multiplex real-time PCR assays for the prediction of cephalosporin, ciprofloxacin and azithromycin antimicrobial susceptibility of positive Neisseria gonorrhoeae nucleic acid amplification test samples. J Antimicrob Chemother. 2020;75(12):3485-90. https://doi.org/10.1093/jac/dkaa360.

69. Lin EY, Adamson PC, Klausner JD. Evaluating the generalizability of a multiplex real-time PCR assay for predicting decreased susceptibility to ceftriaxone in a global set of Neisseria gonorrhoeae sequences. J Antimicrob Chemother. 2020. https://doi. org/10.1093/jac/dkaa525.

70. Lin EY, Adamson PC, Klausner JD. Molecular algorithms accurately predict decreased susceptibility to ceftriaxone in Neisseria gonorrhoeae. Sex Transm Dis. 2020;47(12):e63-4. https://doi. org/10.1097/olq.0000000000001274.

71. Jönsson A, Foerster S, Golparian D, Hamasuna R, Jacobsson S, Lindberg $\mathrm{M}$, et al. In vitro activity and time-kill curve analysis of sitafloxacin against a global panel of antimicrobial-resistant and multidrug-resistant Neisseria gonorrhoeae isolates. APMIS. 2018;126(1):29-37. https://doi.org/10.1111/apm.12777.

72. Hamasuna R, Ohnishi M, Matsumoto M, Okumura R, Unemo $\mathrm{M}$, Matsumoto T. In vitro activity of sitafloxacin and additional newer generation fluoroquinolones against ciprofloxacinresistant Neisseria gonorrhoeae isolates. Microb Drug Resist. 2018;24(1):30-4. https://doi.org/10.1089/mdr.2017.0054.

73. Barbee LA, Golden MR. Aztreonam for Neisseria gonorrhoeae: a systematic review and meta-analysis. J Antimicrob Chemother. 2020;75(7):1685-8. https://doi.org/10.1093/jac/dkaa108.

74. Barbee LA, Soge OO, Ocbamichael N, LeClair A, Golden MR. A single-arm open-label clinical trial of $2 \mathrm{~g}$ aztreonam for the treatment of $N$. gonorrhoeae. Antimicrob Agents Chemother. 2020. https://doi.org/10.1128/aac.01739-20.

75. Rob F, Klubalová B, Nyčová E, Hercogová J, Unemo M. Gentamicin $240 \mathrm{mg}$ plus azithromycin $2 \mathrm{~g}$ vs. ceftriaxone $500 \mathrm{mg}$ plus azithromycin $2 \mathrm{~g}$ for treatment of rectal and pharyngeal gonorrhoea: a randomized controlled trial. Clin Microbiol Infect. 2020;26(2):207-12. https://doi.org/10.1016/j.cmi.2019.08.004.

76. Ross JDC, Brittain C, Cole M, Dewsnap C, Harding J, Hepburn $\mathrm{T}$, et al. Gentamicin compared with ceftriaxone for the treatment of gonorrhoea (G-ToG): a randomised non-inferiority trial. Lancet. 2019;393(10190):2511-20. https://doi.org/10.1016/s01406736(18)32817-4.

77. Fuchs F, Wille J, Hamprecht A, Parcina M, Lehmann C, Schwarze-Zander C, et al. In vitro activity of mecillinam and nitroxoline against Neisseria gonorrhoeae-re-purposing old antibiotics in the multi-drug resistance era. J Med Microbiol. 2019;68(7):991-5. https://doi.org/10.1099/jmm.0.001014.

78. Alhashimi M, Mayhoub A, Seleem MN. Repurposing salicylamide for combating multidrug-resistant Neisseria gonorrhoeae. Antimicrob Agents Chemother. 2019. https://doi.org/10.1128/ aac.01225-19. 
79. Cern A, Connolly KL, Jerse AE, Barenholz Y. In vitro susceptibility of Neisseria gonorrhoeae strains to mupirocin, an antibiotic reformulated for parenteral administration in nanoliposomes. Antimicrob Agents Chemother. 2018. https://doi.org/10.1128/ aac.02377-17.

80. Seong YJ, Alhashimi M, Mayhoub A, Mohammad H, Seleem MN. Repurposing fenamic acid drugs to combat multidrugresistant Neisseria gonorrhoeae. Antimicrob Agents Chemother. 2020. https://doi.org/10.1128/aac.02206-19.

81. Riedel S, Vijayakumar D, Berg G, Kang AD, Smith KP, Kirby JE. Evaluation of apramycin against spectinomycin-resistant and -susceptible strains of Neisseria gonorrhoeae. J Antimicrob Chemother. 2019;74(5):1311-6. https://doi.org/10.1093/jac/ dkz012.

82. Heath NL, Rowlands RS, Webster G, Mahenthiralingam E, Beeton ML. Antimicrobial activity of enacyloxin IIa and gladiolin against the urogenital pathogens Neisseria gonorrhoeae and Ureaplasma spp. J Appl Microbiol. 2020. https://doi.org/10. 1111/jam.14858.

83. Singh V, Bala M, Bhargava A, Kakran M, Bhatnagar R. In vitro efficacy of 21 dual antimicrobial combinations comprising novel and currently recommended combinations for treatment of drug resistant gonorrhoea in future era. PLoS ONE. 2018;13(3):e0193678. https://doi.org/10.1371/journal.pone. 0193678.

84. Elkashif A, Seleem MN. Investigation of auranofin and goldcontaining analogues antibacterial activity against multidrugresistant Neisseria gonorrhoeae. Sci Rep. 2020;10(1):5602. https://doi.org/10.1038/s41598-020-62696-3.

85. Poole J, Day CJ, Haselhorst T, Jen FE, Torres VJ, Edwards JL, et al. Repurposed drugs that block the gonococcus-complement receptor 3 interaction can prevent and cure gonococcal infection of primary human cervical epithelial cells. MBio. 2020. https:// doi.org/10.1128/mBio.03046-19.

86. Basarab GS, Kern GH, McNulty J, Mueller JP, Lawrence K, Vishwanathan K, et al. Responding to the challenge of untreatable gonorrhea: ETX0914, a first-in-class agent with a distinct mechanism-of-action against bacterial Type II topoisomerases. Sci Rep. 2015;5:11827. https://doi.org/10.1038/srep11827.

87. O'Donnell J, Lawrence K, Vishwanathan K, Hosagrahara V, Mueller JP. Single-dose pharmacokinetics, excretion, and metabolism of zoliflodacin, a novel spiropyrimidinetrione antibiotic, in healthy volunteers. Antimicrob Agents Chemother. 2019;63(1):e01808-e1818. https://doi.org/10.1128/aac.01808-18.

88. Huband MD, Bradford PA, Otterson LG, Basarab GS, Kutschke AC, Giacobbe RA, et al. In vitro antibacterial activity of AZD0914, a new spiropyrimidinetrione DNA gyrase/topoisomerase inhibitor with potent activity against Gram-positive, fastidious Gram-Negative, and atypical bacteria. Antimicrob Agents Chemother. 2015;59(1):467-74. https://doi.org/10.1128/ aac.04124-14.

89. Kern G, Palmer T, Ehmann DE, Shapiro AB, Andrews B, Basarab GS, et al. Inhibition of Neisseria gonorrhoeae Type II topoisomerases by the novel spiropyrimidinetrione AZD0914. J Biol Chem. 2015;290(34):20984-94. https://doi.org/10.1074/jbc. M115.663534.

90. Papp JR, Lawrence K, Sharpe S, Mueller J, Kirkcaldy RD. In vitro growth of multidrug-resistant Neisseria gonorrhoeae isolates is inhibited by ETX0914, a novel spiropyrimidinetrione. Int J Antimicrob Agents. 2016;48(3):328-30. https://doi.org/10. 1016/j.ijantimicag.2016.05.018.

91. Jacobsson S, Kularatne R, Kittiyaowamarn R, Maseko V, Paopang $\mathrm{P}$, Sangprasert $\mathrm{P}$, et al. High in vitro susceptibility to the first-in-class spiropyrimidinetrione zoliflodacin among consecutive clinical Neisseria gonorrhoeae isolates from Thailand (2018) and South Africa (2015-2017). Antimicrob Agents Chemother. 2019. https://doi.org/10.1128/aac.01479-19.

92. Unemo M, Ringlander J, Wiggins C, Fredlund H, Jacobsson S, Cole M. High in vitro susceptibility to the novel spiropyrimidinetrione ETX0914 (AZD0914) among 873 contemporary clinical Neisseria gonorrhoeae isolates from 21 European countries from 2012 to 2014. Antimicrob Agents Chemother. 2015;59(9):5220 5. https://doi.org/10.1128/aac.00786-15.

93. Alm RA, Lahiri SD, Kutschke A, Otterson LG, McLaughlin RE, Whiteaker JD, et al. Characterization of the novel DNA gyrase inhibitor AZD0914: low resistance potential and lack of cross-resistance in Neisseria gonorrhoeae. Antimicrob Agents Chemother. 2015;59(3):1478-86. https://doi.org/10.1128/aac. 04456-14.

94. Foerster S, Golparian D, Jacobsson S, Hathaway LJ, Low N, Shafer WM, et al. Genetic resistance determinants, in vitro timekill curve analysis and pharmacodynamic functions for the novel topoisomerase II inhibitor ETX0914 (AZD0914) in Neisseria gonorrhoeae. Front Microbiol. 2015;6:1377. https://doi.org/10. 3389/fmicb.2015.01377.

95. Foerster S, Drusano G, Golparian D, Neely M, Piddock LJV, Alirol E, et al. In vitro antimicrobial combination testing of and evolution of resistance to the first-in-class spiropyrimidinetrione zoliflodacin combined with six therapeutically relevant antimicrobials for Neisseria gonorrhoeae. J Antimicrob Chemother. 2019;74(12):3521-9. https://doi.org/10.1093/jac/dkz376.

96. Taylor SN, Marrazzo J, Batteiger BE, Hook EW, Seña AC, Long $\mathrm{J}$, et al. Single-dose zoliflodacin (ETX0914) for treatment of urogenital gonorrhea. N Engl J Med. 2018;379(19):1835-45. https:// doi.org/10.1056/NEJMoa1706988.

97. Clinicaltrials.gov. https://clinicaltrials.gov/ct2/show/NCT03 959527. Accessed 15 Jan 2021.

98. Golparian D, Fernandes P, Ohnishi M, Jensen JS, Unemo M. In vitro activity of the new fluoroketolide solithromycin (CEM101) against a large collection of clinical Neisseria gonorrhoeae isolates and international reference strains, including those with high-level antimicrobial resistance: potential treatment option for gonorrhea? Antimicrob Agents Chemother. 2012;56(5):2739-42. https://doi.org/10.1128/aac.00036-12.

99. Hook EW III, Golden M, Jamieson BD, Dixon PB, Harbison HS, Lowens S, et al. A phase 2 trial of oral solithromycin 1200 $\mathrm{mg}$ or $1000 \mathrm{mg}$ as single-dose oral therapy for uncomplicated gonorrhea. Clin Infect Dis. 2015;61(7):1043-8. https://doi.org/ 10.1093/cid/civ478.

100. Chen MY, McNulty A, Avery A, Whiley D, Tabrizi SN, Hardy D, et al. Solithromycin versus ceftriaxone plus azithromycin for the treatment of uncomplicated genital gonorrhoea (SOLITAIRE-U): a randomised phase 3 non-inferiority trial. Lancet Infect Dis. 2019;19(8):833-42. https://doi.org/10.1016/s1473-3099(19) 30116-1.

101. Fernandes P, Craft JC. Phase 3 trial of treating gonorrhoea with solithromycin. Lancet Infect Dis. 2019;19(9):928. https://doi.org/ 10.1016/s1473-3099(19)30430-x.

102. Farrell DJ, Sader HS, Rhomberg PR, Scangarella-Oman NE, Flamm RK. In vitro activity of gepotidacin (GSK2140944) against Neisseria gonorrhoeae. Antimicrob Agents Chemother. 2017. https://doi.org/10.1128/aac.02047-16.

103. Jacobsson S, Golparian D, Scangarella-Oman N, Unemo M. In vitro activity of the novel triazaacenaphthylene gepotidacin (GSK2140944) against MDR Neisseria gonorrhoeae. J Antimicrob Chemother. 2018;73(8):2072-7. https://doi.org/10.1093/jac/ dky162.

104. Taylor SN, Morris DH, Avery AK, Workowski KA, Batteiger BE, Tiffany CA, et al. Gepotidacin for the treatment of uncomplicated urogenital gonorrhea: a phase 2, randomized, dose-ranging, 
single-oral dose evaluation. Clin Infect Dis. 2018;67(4):504-12. https://doi.org/10.1093/cid/ciy145.

105. Clinicaltrials.gov. https://clinicaltrials.gov/ct2/show/NCT04 010539. Accessed 15 Jan 2021.

106. Jacobsson S, Mason C, Khan N, Meo P, Unemo M. In vitro activity of the novel oral antimicrobial SMT-571, with a new mechanism of action, against MDR and XDR Neisseria gonorrhoeae: future treatment option for gonorrhoea? J Antimicrob Chemother. 2019;74(6):1591-4. https://doi.org/10.1093/jac/dkz060.

107. Jacobsson S, Mason C, Khan N, Meo P, Unemo M. High in vitro activity of DIS-73285, a novel antimicrobial with a new mechanism of action, against MDR and XDR Neisseria gonorrhoeae. J Antimicrob Chemother. 2020;75(11):3244-7. https://doi.org/ 10.1093/jac/dkaa322.

108. Paukner S, Gruss A, Jensen JS. In vitro activity of lefamulin against sexually transmitted bacterial pathogens. Antimicrob Agents Chemother. 2018. https://doi.org/10.1128/aac.02380-17.

109. Jacobsson S, Paukner S, Golparian D, Jensen JS, Unemo M. In Vitro Activity of the novel pleuromutilin lefamulin (BC-3781) and effect of efflux pump inactivation on multidrug-resistant and extensively drug-resistant Neisseria gonorrhoeae. Antimicrob Agents Chemother. 2017. https://doi.org/10.1128/aac.01497-17.

110. Veve MP, Wagner JL. Lefamulin: review of a promising novel pleuromutilin antibiotic. Pharmacotherapy. 2018;38(9):935-46. https://doi.org/10.1002/phar.2166.

111. Butler MM, Waidyarachchi SL, Connolly KL, Jerse AE, Chai W, Lee RE, et al. Aminomethyl spectinomycins as therapeutics for drug-resistant gonorrhea and chlamydia coinfections. Antimicrob Agents Chemother. 2018. https://doi.org/10.1128/aac.00325-18.

112. Miari VF, Solanki P, Hleba Y, Stabler RA, Heap JT. In vitro susceptibility to closthioamide among clinical and reference strains of Neisseria gonorrhoeae. Antimicrob Agents Chemother. 2017. https://doi.org/10.1128/aac.00929-17.

113. Muratani T, Doi K, Kobayashi T, Nakamura T, Matsumoto T. Antimicrobial activity of tebipenem against various clinical isolates from various specimen, mainly urinary tract. Jpn J Antibiot. 2009;62(2):116-26.

114. Muir LA, Walpole SM, Warfel PA, Kwak H, Phelan A-M, Moore GE, et al. LB-3. Oral tebipenem pivoxil hydrobromide is non-inferior TO IV ertapenem in complicated urinary tract infection (cUTI) and acute pyelonephritis (AP)—results from the pivotal ADAPT-PO Study. Open Forum Infect Dis. 2020;7(Supplement_1):S844-5. https://doi.org/10.1093/ofid/ ofaa515.1900.

115. Critchley IA, Cotroneo NS, Pucci MJ, Jain A, Mendes RE. 1695. Tebipenem: an oral carbapenem with activity against multi-drug resistant urinary tract infection isolates of Escherichia coli collected from US Medical Centers during 2019. Open Forum Infect Dis. 2020;7(Supplement_1):S831-S. https://doi.org/10.1093/ofid/ ofaa439.1873.

116. Martin JK 2nd, Sheehan JP, Bratton BP, Moore GM, Mateus A, $\mathrm{Li} \mathrm{SH}$, et al. A dual-mechanism antibiotic kills gram-negative bacteria and avoids drug resistance. Cell. 2020;181(7):1518-32. e14. https://doi.org/10.1016/j.cell.2020.05.005.

117. Jacobsson S, Alirol E, Unemo M. In vitro activity of the ketolide cethromycin in multidrug-resistant clinical Neisseria gonorrhoeae isolates and international reference strains. J Chemother. 2019;31(5):246-51. https://doi.org/10.1080/1120009x.2019. 1615724.

118. Yarlagadda V, Medina R, Johnson TA, Koteva KP, Cox G, Thaker $\mathrm{MN}$, et al. Resistance-guided discovery of elfamycin antibiotic producers with antigonococcal activity. ACS Infect Dis. 2020. https://doi.org/10.1021/acsinfecdis.0c00467.

119. Sun Y, Zhang J, Zhang Y, Liu J, van der Veen S, Duttwyler S. The closo-dodecaborate dianion fused with oxazoles provides 3D diboraheterocycles with selective antimicrobial activity.
Chemistry (Easton). 2018;24(41):10364-71. https://doi.org/10. 1002/chem.201801602.

120. John CM, Li M, Feng D, Jarvis GA. Cationic cell-penetrating peptide is bactericidal against Neisseria gonorrhoeae. J Antimicrob Chemother. 2019;74(11):3245-51. https://doi.org/10.1093/ jac/dkz339.

121. Lucío MI, Kyriazi ME, Hamilton J, Batista D, Sheppard A, Sams-Dodd E, et al. Bactericidal effect of 5-mercapto-2-nitrobenzoic acid-coated silver nanoclusters against multidrugresistant Neisseria gonorrhoeae. ACS Appl Mater Interfaces. 2020;12(25):27994-8003. https://doi.org/10.1021/acsami.0c061 63.

122. Wang Y, Ferrer-Espada R, Baglo Y, Goh XS, Held KD, Grad YH, et al. Photoinactivation of Neisseria gonorrhoeae: a paradigmchanging approach for combating antibiotic-resistant gonococcal infection. J Infect Dis. 2019;220(5):873-81. https://doi.org/10. 1093/infdis/jiz018.

123. Oliveira H, Sillankorva S, Merabishvili M, Kluskens LD, Azeredo J. Unexploited opportunities for phage therapy. Front Pharmacol. 2015;6:180. https://doi.org/10.3389/fphar.2015. 00180.

124. Lin DM, Koskella B, Lin HC. Phage therapy: an alternative to antibiotics in the age of multi-drug resistance. World J Gastrointest Pharmacol Ther. 2017;8(3):162-73. https://doi.org/10.4292/ wjgpt.v8.i3.162.

125. Chow EPF, Maddaford K, Hocking JS, Bradshaw CS, Wigan $\mathrm{R}$, Chen MY, et al. An open-label, parallel-group, randomised controlled trial of antiseptic mouthwash versus antibiotics for oropharyngeal gonorrhoea treatment (OMEGA2). Sci Rep. 2020;10(1):19386. https://doi.org/10.1038/s41598-020-76184-1.

126. Semchenko EA, Everest-Dass AV, Jen FE, Mubaiwa TD, Day CJ, Seib KL. Glycointeractome of Neisseria gonorrhoeae: identification of host glycans targeted by the gonococcus to facilitate adherence to cervical and urethral epithelial cells. MBio. 2019. https://doi.org/10.1128/mBio.01339-19.

127. Semchenko EA, Mubaiwa TD, Day CJ, Seib KL. Role of the gonococcal neisserial heparin binding antigen in microcolony formation, and serum resistance and adherence to epithelial cells. J Infect Dis. 2020;221(10):1612-22. https://doi.org/10.1093/infdis/jiz628.

128. Ragland SA, Humbert MV, Christodoulides M, Criss AK. Neisseria gonorrhoeae employs two protein inhibitors to evade killing by human lysozyme. PLoS Pathog. 2018;14(7):e1007080. https:// doi.org/10.1371/journal.ppat.1007080.

129. Kammerman MT, Bera A, Wu R, Harrison SA, Maxwell CN, Lundquist K, et al. Molecular insight into TdfH-mediated zinc piracy from human calprotectin by Neisseria gonorrhoeae. MBio. 2020. https://doi.org/10.1128/mBio.00949-20.

130. Sikora AE, Wierzbicki IH, Zielke RA, Ryner RF, Korotkov KV, Buchanan SK, et al. Structural and functional insights into the role of BamD and BamE within the $\beta$-barrel assembly machinery in Neisseria gonorrhoeae. J Biol Chem. 2018;293(4):1106-19. https://doi.org/10.1074/jbc.RA117.000437.

131. Craig AP, Gray RT, Edwards JL, Apicella MA, Jennings MP, Wilson DP, et al. The potential impact of vaccination on the prevalence of gonorrhea. Vaccine. 2015;33(36):4520-5. https:// doi.org/10.1016/j.vaccine.2015.07.015.

132. Greenberg L, Diena BB, Ashton FA, Wallace R, Kenny CP, Znamirowski $\mathrm{R}$, et al. Gonococcal vaccine studies in Inuvik. Can J Public Health. 1974;65(1):29-33.

133. Greenberg L. Field trials of a gonococcal vaccine. J Reprod Med. 1975;14(1):34-6.

134. Russell MW. Could vaccination against Neisseria gonorrhoeae be on the horizon? Future Microbiol. 2018;13:495-7. https:// doi.org/10.2217/fmb-2017-0262. 
135. Tramont EC, Boslego JW. Pilus vaccines. Vaccine. 1985;3(1):3-10. https://doi.org/10.1016/0264-410x(85) 90003-9.

136. Boslego JW, Tramont EC, Chung RC, McChesney DG, Ciak J, Sadoff JC, et al. Efficacy trial of a parenteral gonococcal pilus vaccine in men. Vaccine. 1991;9(3):154-62. https://doi.org/10. 1016/0264-410x(91)90147-x.

137. Gottlieb SL, Deal CD, Giersing B, Rees H, Bolan G, Johnston C, et al. The global roadmap for advancing development of vaccines against sexually transmitted infections: update and next steps. Vaccine. 2016;34(26):2939-47. https://doi.org/10.1016/j.vacci ne.2016.03.111.

138. Vincent LR, Jerse AE. Biological feasibility and importance of a gonorrhea vaccine for global public health. Vaccine. 2019;37(50):7419-26. https://doi.org/10.1016/j.vaccine.2018. 02.081 .

139. Zughaier SM, Kandler JL, Shafer WM. Neisseria gonorrhoeae modulates iron-limiting innate immune defenses in macrophages. PLoS ONE. 2014;9(1):e87688. https://doi.org/10.1371/journal. pone.0087688.

140. Feinen B, Jerse AE, Gaffen SL, Russell MW. Critical role of Th17 responses in a murine model of Neisseria gonorrhoeae genital infection. Mucosal Immunol. 2010;3(3):312-21. https:// doi.org/10.1038/mi.2009.139.

141. Liu Y, Islam EA, Jarvis GA, Gray-Owen SD, Russell MW. Neisseria gonorrhoeae selectively suppresses the development of Th1 and Th2 cells, and enhances Th17 cell responses, through TGF$\beta$-dependent mechanisms. Mucosal Immunol. 2012;5(3):320-31. https://doi.org/10.1038/mi.2012.12.

142. Zhu W, Ventevogel MS, Knilans KJ, Anderson JE, Oldach LM, McKinnon KP, et al. Neisseria gonorrhoeae suppresses dendritic cell-induced, antigen-dependent CD4 T cell proliferation. PLoS ONE. 2012;7(7):e41260. https://doi.org/10.1371/journal.pone.0041260.

143. Duncan JA, Gao X, Huang MT, O'Connor BP, Thomas CE, Willingham $\mathrm{SB}$, et al. Neisseria gonorrhoeae activates the proteinase cathepsin B to mediate the signaling activities of the NLRP3 and ASC-containing inflammasome. J Immunol. 2009;182(10):64609. https://doi.org/10.4049/jimmunol.0802696.

144. Pajon R, Buckwalter CM, Johswich KO, Gray-Owen SD, Granoff DM. A native outer membrane vesicle vaccine confers protection against meningococcal colonization in human CEACAM1 transgenic mice. Vaccine. 2015;33(11):1317-23. https://doi.org/ 10.1016/j.vaccine.2015.01.057.

145. Zarantonelli ML, Szatanik M, Giorgini D, Hong E, Huerre M, Guillou F, et al. Transgenic mice expressing human transferrin as a model for meningococcal infection. Infect Immun. 2007;75(12):5609-14. https://doi.org/10.1128/iai.00781-07.

146. Ermert D, Shaughnessy J, Joeris T, Kaplan J, Pang CJ, Kurt-Jones EA, et al. Virulence of group A streptococci is enhanced by human complement inhibitors. PLoS Pathog. 2015;11(7):e1005043. https://doi.org/10.1371/journal.ppat. 1005043.

147. Islam EA, Shaik-Dasthagirisaheb Y, Kaushic C, Wetzler LM, Gray-Owen SD. The reproductive cycle is a pathogenic determinant during gonococcal pelvic inflammatory disease in mice. Mucosal Immunol. 2016;9(4):1051-64. https://doi.org/10.1038/ mi.2015.122.

148. Petousis-Harris H, Paynter J, Morgan J, Saxton P, McArdle B, Goodyear-Smith F, et al. Effectiveness of a group B outer membrane vesicle meningococcal vaccine against gonorrhoea in New Zealand: a retrospective case-control study. Lancet. 2017;390(10102):1603-10. https://doi.org/10.1016/s01406736(17)31449-6.

149. Paynter J, Goodyear-Smith F, Morgan J, Saxton P, Black S, Petousis-Harris H. Effectiveness of a group B outer membrane vesicle meningococcal vaccine in preventing hospitalization from gonorrhea in New Zealand: a retrospective cohort study. Vaccines (Basel). 2019. https://doi.org/10.3390/vaccines7010005.

150. Kenyon C. Comment on "Effectiveness of a Group B outer membrane vesicle meningococcal vaccine in preventing hospitalization from gonorrhea in New Zealand: a retrospective cohort study, Vaccines, 2019, 1, 5; doi:10.3390/vaccines7010005. Vaccines (Basel). 2019. https://doi.org/10.3390/vaccines7010031.

151. Paynter J, Goodyear-Smith F, Morgan J, Saxton P, Black S, Petousis-Harris H. Reply to "Comment on Effectiveness of a Group B Outer Membrane Vesicle Meningococcal Vaccine in Preventing Hospitalization from Gonorrhea in New Zealand: A Retrospective Cohort Study, Vaccines, 2019, 1, 5; doi:10.3390/ vaccines7010005." Vaccines (Basel). 2019. https://doi.org/10. 3390/vaccines7010032.

152. Azze RFO. A meningococcal B vaccine induces cross-protection against gonorrhea. Clin Exp Vaccine Res. 2019;8(2):110-5. https://doi.org/10.7774/cevr.2019.8.2.110.

153. Whelan J, Kløvstad H, Haugen IL, Holle MR-DRB, Storsaeter J. Ecologic study of meningococcal B vaccine and Neisseria gonorrhoeae infection Norway. Emerg Infect Dis. 2016;22(6):1137-9. https://doi.org/10.3201/eid2206.151093.

154. Semchenko EA, Tan A, Borrow R, Seib KL. The serogroup B meningococcal vaccine bexsero elicits antibodies to Neisseria gonorrhoeae. Clin Infect Dis. 2019;69(7):1101-11. https://doi. org/10.1093/cid/ciy1061.

155. Leduc I, Connolly KL, Begum A, Underwood K, Darnell $\mathrm{S}$, Shafer WM, et al. The serogroup B meningococcal outer membrane vesicle-based vaccine $4 \mathrm{CMenB}$ induces cross-species protection against Neisseria gonorrhoeae. PLoS Pathog. 2020;16(12):e1008602. https://doi.org/10.1371/journal.ppat. 1008602 .

156. Clinicaltrials.gov. https://clinicaltrials.gov/ct2/show/NCT04 350138. Accessed 15 Jan 2021.

157. Gala RP, Zaman RU, D'Souza MJ, Zughaier SM. Novel wholecell inactivated Neisseria gonorrhoeae microparticles as vaccine formulation in microneedle-based transdermal immunization. Vaccines (Basel). 2018. https://doi.org/10.3390/vaccines60 30060.

158. Jiao H, Yang H, Zhao D, Chen J, Zhang Q, Liang J, et al. Design and immune characterization of a novel Neisseria gonorrhoeae DNA vaccine using bacterial ghosts as vector and adjuvant. Vaccine. 2018;36(30):4532-9. https://doi.org/10.1016/j.vacci ne.2018.06.006.

159. Wang L, Xing D, Le Van A, Jerse AE, Wang S. Structurebased design of ferritin nanoparticle immunogens displaying antigenic loops of Neisseria gonorrhoeae. FEBS Open Bio. 2017;7(8):1196-207. https://doi.org/10.1002/2211-5463.12267.

160. Kanekiyo M, Wei CJ, Yassine HM, McTamney PM, Boyington JC, Whittle JR, et al. Self-assembling influenza nanoparticle vaccines elicit broadly neutralizing $\mathrm{H} 1 \mathrm{~N} 1$ antibodies. Nature. 2013;499(7456):102-6. https://doi.org/10.1038/nature12202.

161. Kanekiyo M, Bu W, Joyce MG, Meng G, Whittle JR, Baxa U, et al. Rational design of an epstein-barr virus vaccine targeting the receptor-binding site. Cell. 2015;162(5):1090-100. https:// doi.org/10.1016/j.cell.2015.07.043.

162. Zielke RA, Wierzbicki IH, Baarda BI, Gafken PR, Soge OO, Holmes KK, et al. Proteomics-driven antigen discovery for development of vaccines against gonorrhea. Mol Cell Proteomics. 2016;15(7):2338-55. https://doi.org/10.1074/mcp.M116.058800.

163. Gulati S, Shaughnessy J, Ram S, Rice PA. Targeting lipooligosaccharide (LOS) for a gonococcal vaccine. Front Immunol. 2019;10:321. https://doi.org/10.3389/fimmu.2019.00321.

164. Gulati S, Pennington MW, Czerwinski A, Carter D, Zheng B, Nowak NA, et al. Preclinical efficacy of a lipooligosaccharide peptide mimic candidate gonococcal vaccine. MBio. 2019. https://doi.org/10.1128/mBio.02552-19. 
165. Brott AS, Jones CS, Clarke AJ. Development of a high throughput screen for the identification of inhibitors of peptidoglycan $O$-acetyltransferases, new potential antibacterial targets. Antibiotics (Basel). 2019. https://doi.org/10.3390/antibiotics8020065.

166. Bettoni S, Shaughnessy J, Maziarz K, Ermert D, Gulati S, Zheng $\mathrm{B}$, et al. C4BP-IgM protein as a therapeutic approach to treat Neisseria gonorrhoeae infections. JCI Insight. 2019. https://doi. org/10.1172/jci.insight.131886.

167. Gulati S, Schoenhofen IC, Lindhout-Djukic T, Lewis LA, Moustafa IY, Saha S, et al. Efficacy of antigonococcal CMPnonulosonate therapeutics require cathelicidins. J Infect Dis. 2020;222(10):1641-50. https://doi.org/10.1093/infdis/jiaa438.

168. Shaughnessy J, Lewis LA, Zheng B, Carr C, Bass I, Gulati S, et al. Human factor $\mathrm{H}$ domains 6 and 7 fused to IgG1 $\mathrm{Fc}$ are immunotherapeutic against Neisseria gonorrhoeae. J Immunol. 2018;201(9):2700-9. https://doi.org/10.4049/jimmunol.1701666.

169. Barrett KF, Dranow DM, Phan IQ, Michaels SA, Shaheen S, Navaluna ED, et al. Structures of glyceraldehyde 3-phosphate dehydrogenase in Neisseria gonorrhoeae and Chlamydia trachomatis. Protein Sci. 2020;29(3):768-78. https://doi.org/10. $1002 /$ pro. 3824 .

170. John CM, Feng D, Jarvis GA. Treatment of human challenge and MDR strains of Neisseria gonorrhoeae with LpxC inhibitors. J Antimicrob Chemother. 2018;73(8):2064-71. https://doi.org/10. 1093/jac/dky151.

171. Wang Z, Wang X, Lu P, Ni C, Li Y, van der Veen S. Identification and characterization of the Neisseria gonorrhoeae MscS-like mechanosensitive channel. Infect Immun. 2018. https://doi.org/ 10.1128/iai.00090-18.

172. Chen S, Connolly KL, Rouquette-Loughlin C, D'Andrea A, Jerse AE, Shafer WM. Could dampening expression of the Neisseria gonorrhoeae mtrCDE-encoded efflux pump be a strategy to preserve currently or resurrect formerly used antibiotics to treat gonorrhea? MBio. 2019. https://doi.org/10.1128/mBio.01576-19.

173. Zhu T, McClure R, Harrison OB, Genco C, Massari P. Integrated bioinformatic analyses and immune characterization of new Neisseria gonorrhoeae vaccine antigens expressed during natural mucosal infection. Vaccines (Basel). 2019. https://doi. org/10.3390/vaccines7040153.
174. Sikora AE, Gomez C, Le Van A, Baarda BI, Darnell S, Martinez FG, et al. A novel gonorrhea vaccine composed of MetQ lipoprotein formulated with $\mathrm{CpG}$ shortens experimental murine infection. Vaccine. 2020. https://doi.org/10.1016/j.vaccine.2020. 10.077 .

175. Wang S, Xue J, Lu P, Ni C, Cheng H, Han R, et al. Gonococcal MtrE and its surface-expressed loop 2 are immunogenic and elicit bactericidal antibodies. J Infect. 2018;77(3):191-204. https://doi.org/10.1016/j.jinf.2018.06.001.

176. Almonacid-Mendoza HL, Humbert MV, Dijokaite A, Cleary DW, Soo Y, Hung MC, et al. Structure of the recombinant neisseria gonorrhoeae adhesin complex protein ( $\mathrm{rNg}-\mathrm{ACP})$ and generation of murine antibodies with bactericidal activity against gonococci. mSphere. 2018. https://doi.org/10.1128/mSphere.00331-18.

177. Humbert MV, Christodoulides M. Immunization with recombinant truncated Neisseria meningitidis-macrophage infectivity potentiator (rT-Nm-MIP) protein induces murine antibodies that are cross-reactive and bactericidal for Neisseria gonorrhoeae. Vaccine. 2018;36(27):3926-36. https://doi.org/10.1016/j.vacci ne.2018.05.069.

178. Price GA, Russell MW, Cornelissen CN. Intranasal administration of recombinant Neisseria gonorrhoeae transferrin binding proteins $\mathrm{A}$ and $\mathrm{B}$ conjugated to the cholera toxin $\mathrm{B}$ subunit induces systemic and vaginal antibodies in mice. Infect Immun. 2005;73(7):3945-53. https://doi.org/10.1128/iai.73.7.3945-3953. 2005.

179. Cash DR, Noinaj N, Buchanan SK, Cornelissen CN. Beyond the crystal structure: insight into the function and vaccine potential of TbpA expressed by Neisseria gonorrhoeae. Infect Immun. 2015;83(11):4438-49. https://doi.org/10.1128/iai.00762-15.

180. Shewell LK, Ku SC, Schulz BL, Jen FE, Mubaiwa TD, Ketterer MR, et al. Recombinant truncated AniA of pathogenic Neisseria elicits a non-native immune response and functional blocking antibodies. Biochem Biophys Res Commun. 2013;431(2):21520. https://doi.org/10.1016/j.bbrc.2012.12.132.

181. Zhu W, Chen CJ, Thomas CE, Anderson JE, Jerse AE, Sparling PF. Vaccines for gonorrhea: can we rise to the challenge? Front Microbiol. 2011;2:124. https://doi.org/10.3389/fmicb.2011.00124. 